\title{
Three-Dimensional Model-Observation Comparison in the Loop Current Region
}

\author{
K. C. Rosburga, ${ }^{\mathrm{a}, 1, *}$, K. A. Donohue ${ }^{\mathrm{a}}$, E. P. Chassignet ${ }^{\mathrm{b}}$ \\ ${ }^{a}$ Graduate School of Oceanography, University of Rhode Island, Narragansett, Rhode \\ Island, USA \\ ${ }^{b}$ Center for Ocean-Atmosphere Prediction Studies, Florida State University, Tallahassee, \\ Florida, USA
}

\begin{abstract}
Accurate high-resolution ocean models are required for hurricane and oil spill pathway predictions, and to enhance the dynamical understanding of circulation dynamics. Output from the $1 / 25^{\circ}$ data-assimilating Gulf of Mexico HYbrid Coordinate Ocean Model (HYCOM31.0) is compared to daily full water column observations from a moored array, with a focus on Loop Current path variability and upper-deep layer coupling during eddy separation. Array-mean correlation was 0.93 for sea surface height, and 0.93, 0.63, and 0.75 in the thermocline for temperature, zonal, and meridional velocity, respectively. Peaks in modeled eddy kinetic energy were consistent with observations during Loop Current eddy separation, but with modeled deep eddy kinetic energy at half the observed amplitude. Modeled and observed LC meander phase speeds agreed within $8 \%$ and $2 \%$ of each other within the

\footnotetext{
${ }^{*}$ Corresponding author

Email addresses: rosburk@my.uri.edu (K. C. Rosburg), kdonohue@uri.edu (K.

${ }^{1}$ Now at: School of Ocean and Earth Science and Technology, University of Hawaii at
} A. Donohue), echassignet@fsu.edu (E. P. Chassignet) Manoa, Honolulu, Hawaii, USA (krosburg@hawaii.edu)
\end{abstract}


100-40 and 40-20 day bands, respectively. The model reproduced observed patterns indicative of baroclinic instability, that is, a vertical offset with deep stream function leading upper stream function in the along-stream direction. While modeled deep eddies differed slightly spatially and temporally, the joint development of an upper-ocean meander along the eastern side of the LC and the successive propagation of upper-deep cyclone/anticylone pairs that preceded separation were contained within the model solution. Overall, model-observation comparison indicated that HYCOM31.0 could provide insight into processes within the 100-20 day band, offering a larger spatial and temporal window than observational arrays.

Keywords: Evaluation, Modelling, Ocean currents, Mesoscale eddies, Baroclinic instability, USA, Gulf of Mexico, Loop Current

\section{1. Introduction}

As part of the North Atlantic subtropical western boundary current sys3 tem, the Loop Current (LC) enters the Gulf of Mexico (GOM) from the 4 Caribbean Sea as the continuation of the Yucatán Current (YC), circu5 lates anticyclonically within the Gulf forming a large loop, exits through the 6 Florida Straits, and becomes the Florida Current after turning north along 7 the eastern side of Florida. On irregular intervals, between 3-17 months, 8 a large (200-400 km diameter) anticyclonic eddy, a LC Eddy (LCE), sepa9 rates from the LC (Sturges and Leben, 2000; Dukhovskoy et al., 2015). The separation process, shown schematically in Figure 1, begins with the northward intrusion of the LC into the GOM, followed by the necking down of the LC and eventual pinching-off of a LCE. After separation, the LC re- 
treats southward to the so-called port-to-port mode while the newly shed LCE propagates westward across the Gulf.

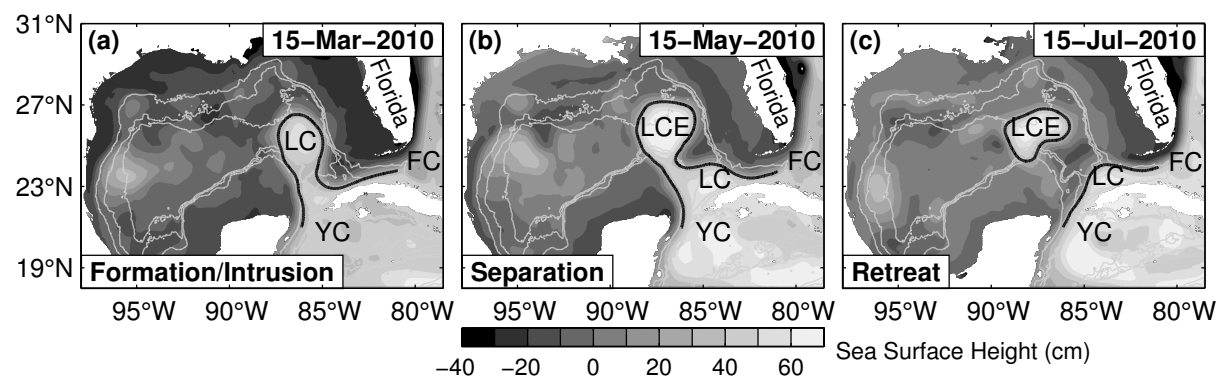

Figure 1: Maps of sea surface height depicting the three-stage Loop Current Eddy cycle: (a) northward intrusion/growth of the Loop Current (LC), (b) pinch-off of the anticyclonic ring, and (c) final separation and subsequent westward propagation of the eddy, and retreat of the LC to port-to-port mode. FC is Florida Current. YC is Yucatan Current. Sea surface height from the $1 / 25^{\circ}$ Gulf of Mexico Hybrid Coordinate Ocean Model, GOMl0.04 expt_31.0.

There is a strong need for predictive skill for LCE separation. For example, strong currents associated with the LC and LCEs, as well as the strong deep currents generated during LCE separation, are hazardous to deep-water oil drilling operations. The warm cores of LCEs are also known to modify the intensity of passing hurricanes (e.g. Cione and Uhlhorn 2003; Yablonsky and Ginis 2012; Lin et al. 2008). Deep circulation, especially along the steep escarpments of the Gulf's continental slope play an important role in the rapid dispersal of contaminants (e.g. Paris et al. 2012; Nguyen et al. 2015).

Efforts have been made to predict and model LCE separation. Using an idealized vorticity model, Lugo-Fernández and Leben (2010) confirmed a linear relationship between the latitude of LC retreat and the length of time between LCE separations, a trend previously seen in satellite altime- 
try (Leben, 2005). Maul (1977) hypothesized a linkage between the rate of change of LC volume and deep transport through the Yucatán Channel. This idea is supported by 7.5 months of YC mooring observations (Bunge et al., 2002) and the recent analysis of a 54-year free-running $1 / 25^{\circ}$ model (Nedbor-Gross et al., 2014). Chang and Oey (2011), on the other hand, suggest that mass exchange between the eastern and western basins, as well as exchange between the LC and deeper waters, play a significant role in the separation process. Evidence has been found for both seasonal (Leben et al., 2012; Chang and Oey, 2012) and inter-annual (Lugo-Fernández, 2007) trends in the length of the eddy separation period. Recent modeling studies suggest that seasonality in the trade winds may affect LCE separation (e.g. Chang and Oey 2013; Xu et al. 2013). Using an artificial neural network approach, Zeng et al. (2015) achieved reliable LCE shedding forecasts of up to four weeks in SSH. Numerical studies also point to the importance of instability processes, the coupling between upper and deep circulation, and the generation of bursts of strong deep eddies during LCE separation. Examining instabilities exhibited in upper and deep pressure fields of a two-layer model, Hurlburt and Thompson $(1980,1982)$ found deep circulation driven by mixed baroclinic and barotropic instabilities. During LCE separation and detachment events, deep circulation is dominated by a field of intense deep eddies that propagate and couple with vortices of the upper-ocean LC (Sturges et al., 1993; Chérubin et al., 2005). Baroclinic instabilities near Campeche Bank and the West Florida Shelf have also been identified as a possible mechanism for the generation of deep eddies that facilitate LCE detachment (Chérubin et al., 2005; Oey, 2008). Finally, Le Hénaff et al. (2012) suggest that deep 
eddies spin up as the LC moves off the Mississippi Fan. How well numerical models predict or simulate deep currents is not well documented owing to sparse observations of circulation below the surface and in particular below the thermocline.

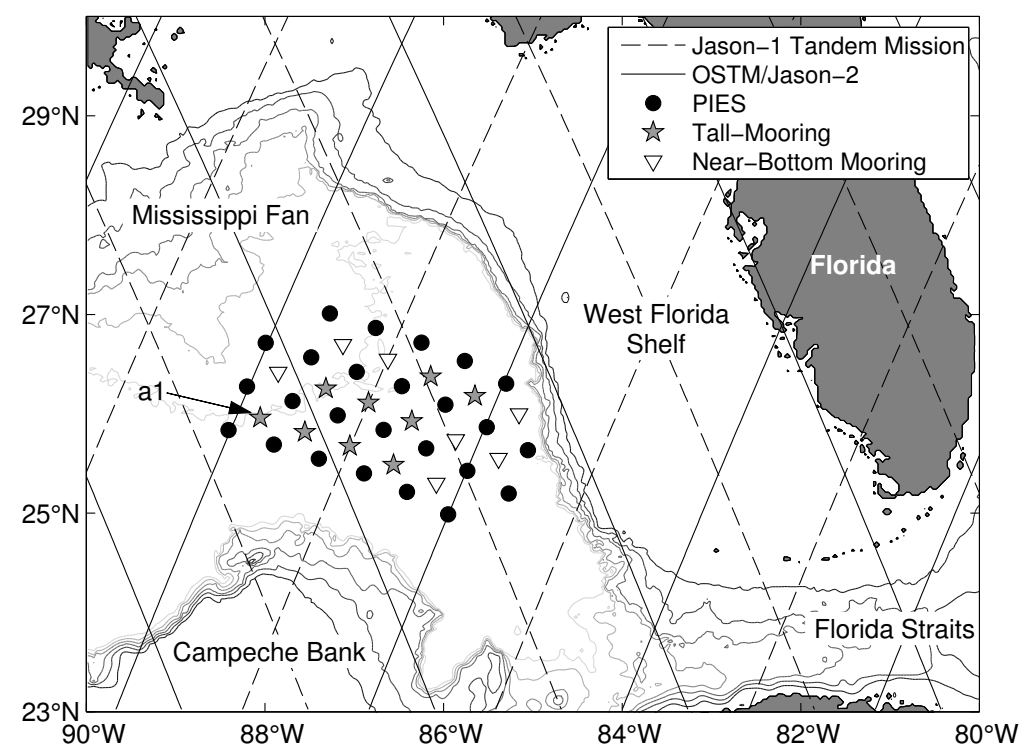

Figure 2: Map of DynLoop mooring array, indicating locations of tall-moorings (gray filled stars), near-bottom moorings (triangles), and PIES (black filled circles), along with satellite altimeter exact repeat ground track coverage for OSTM/Jason-2 (solid) and Jason1 tandem mission (dashed), as well as bathymetry (gray contours) at $500 \mathrm{~m}$ intervals.

In 2009, a comprehensive field study "Observations and Dynamics of the Loop Current" (DynLoop) was undertaken. Funded by the Bureau of Ocean Energy Management (BOEM), DynLoop aimed to investigate LC circulation dynamics, eddy-shedding mechanisms, and forcing of deep flow. The study utilized an in situ mapping array centered in the LC (Figure 2) that included nine full water column (tall) moorings, seven near-bottom moorings, and 25 
pressure sensing inverted echo sounders (PIES). The array provides a unique dataset for studying the LCE cycle: it was centered in the region of LCE formation/separation and during its 30-month deployment observed four LCE events with daily measurements throughout the water column at mesoscale resolution. The dataset from this study provides critical deep-velocity information required for a comprehensive 3D model-data comparison. Hamilton et al. (2016) provides a review of the study.

Through advances in modeling, advanced assimilation techniques, and increased computational power, modern predictive ocean models reproduce surface currents to a high degree of accuracy. One example is the HYbrid Coordinate Ocean Model (HYCOM). Because of the demonstrated application of global- and basin-scale real time ocean predictions, the US Navy has transitioned HYCOM into operational use at the Naval Oceanographic Office (NAVOCEANO; Chassignet et al. 2009; Cummings and Smedstad 2013; Metzger et al. 2014). The high-resolution $1 / 25^{\circ}$ regional-scale data-assimilative GOM HYCOM has undergone a number of improvements; the current version (at the time of writing), GOMl0.04 expt_31.0 (hereafter HYCOM31.0) is one of the highest resolution and most advanced data-assimilative numerical models available for studies and predictions of GOM circulation. HYCOM31.0 assimilates predominately surface measurements from remotely sensed satellite altimetry and temperature, as well as temperature and salinity profiles, but does not incorporate deep (> $2000 \mathrm{~m}$ ) observations. Previous validation of HYCOM includes comparison to other models, satellite SST, SSS (salinity), SSH, and ocean color (Chassignet et al., 2005, 2007, 2009), to satellite-tracked surface drifters (Liu and Weisberg, 2011; Liu et al., 2014), 
and to airborne profiles of near-surface temperature and $20^{\circ} \mathrm{C}$ isotherm depth (Shay et al., 2011). Scott et al. (2010) did compare global HYCOM ocean forecasting systems to a global current meter record dataset that included observations below $2000 \mathrm{~m}$ depth, but comprehensive comparisons to deep (> $2000 \mathrm{~m}$ depth) observations in the GOM are lacking. Other recent assimilation efforts, Kantha et al. (2005); Yin and Oey (2007); Xu et al. (2013); Gopalakrishnan et al. (2013b), have been made in the Gulf of Mexico. A comprehensive review is beyond the scope of this study, which focuses upon HYCOM31.0.

The overarching goal of this study is to assess the viability of HYCOM31.0 for use in studies of mesoscale LC processes. Here, we focus on two aspects: LC path variability and vertical coupling between the upper and deep circulation during LCE separation. The term LC Frontal Eddy (LCFE) has been applied to describe variability along the LC path (see Le Hénaff et al. 2014 for a comprehensive review). LCFEs are thought to play a role in LCE separation (e.g. Cochrane 1972; Chérubin et al. 2005; Schmitz 2005). In SST and $\mathrm{SSH}$, this variability appears as LC meanders and cyclonic eddy-like features that propagate along the LC path (e.g. Walker et al. 2003). Here, we choose to term variability along the LC path as "LC meanders" rather then LC Frontal Eddies to reinforce the concept that the rich variability along the LC path encompasses a wide range of spatial and temporal scales, and more importantly that multiple dynamical processes are likely responsible for the variability.

The DynLoop analysis of LC meanders determined that within the mesoscale band (3-100 day periods), wavelengths are between $230 \mathrm{~km}$ to $460 \mathrm{~km}$ with 
phase speeds ranging between 8 to $50 \mathrm{~km} \mathrm{~d}^{-1}$ (Donohue et al., 2015). Moreover, that study and Le Hénaff et al. (2014) demonstrate that variability is strongest for periods between 40 and 100 days. Long-wavelength lowfrequency meanders were found to be restricted to east of LC, corroborating the early findings of Vukovich (1988) and the recent analysis of Le Hénaff et al. (2014). These long-wavelength meanders form along the eastern edge of the LC prior to eddy separation. Development of the upper meander is accompanied by elevated deep eddy kinetic energy and the formation of a deep cyclone (anticyclone), which leads the upper-ocean meander trough (crest) by roughly a quarter wavelength in a pattern consistent with baroclinic instability (Donohue et al., 2016).

Observational studies are inherently limited both spatially and temporally, and numerical simulations provide the larger space and time window required for a deeper dynamical understanding. For example, we ultimately seek to determine what triggers the growth of long-wavelength low-frequency meanders, the role of topography in stabilizing or destabilizing the LC, and how topography dictates the pathways of the deep energy generated during LCE formation. This preliminary 3D comparison is a necessary first step in order to use the model for dynamical interpretation.

A detailed description of the observations, HYCOM31.0, and methodologies used in this study is provided in Section 2. Section 3 outlines the findings of our time series and point-to-point statistical comparisons, followed by the results of broad-scale spatial comparisons (SSH variance and EKE distributions) in Section 4. In Section 5, we present a phenomenological comparison of a subset of the processes involved in the LCE cycle. The results of this 
study are discussed in the broader context of the literature in Section 6 .

\section{Data \& Methods}

\subsection{Observations}

Observations derive from the comprehensive DynLoop field study in the GOM, which included a large mooring array centered near $26^{\circ} \mathrm{N} 87^{\circ} \mathrm{W}$ (Figure 2). This array produced a unique dataset: the array, deployed for nominally 30 months from April 2009 to November 2011, captured three LCE separations and the initial detachment of a fourth LCE; the instrumentation provided full water column observations; and the instrument spacing resolved the mesoscale circulation. Details regarding the full suite of instrumentation and processing are provided in Hamilton et al. (2014).

Nine tall moorings sampled the full water column. Point current meters recorded velocities at 600, 900, 1300, and 2000 meters depth, with additional current meters located 100 meters above bottom (mab). Near-surface currents were profiled by an upward-looking $75 \mathrm{kHz}$ ADCP situated at 450 meters depth. Temperature sensors were located at 75, 150, 250, 350, 525, $600,750,900,1100,1300,1500$, and 2000 meters depth, as well as 100 mab. Seven additional near-bottom moorings had a single current meter 100 mab. Twenty-five PIES were deployed with a horizontal resolution of $\sim 53 \mathrm{~km}$. PIES, moored at the ocean floor, record bottom pressure and the round trip travel time, $\tau$, of emitted $12 \mathrm{kHz}$ sound pulses. Mooring velocity, temperature, $\tau$, and bottom pressure were filtered with a 72 -hour $4^{\text {th }}$ order low-pass Butterworth filter and subsampled at 24-hour intervals. A subset of PIES and tall moorings were aligned along altimeter ground tracks (Figure 2). 
Vertical profiles of temperature, salinity, and specific volume anomaly were calculated from $\tau$ using look-up tables (e.g., gravest empirical mode, GEM; Meinen and Watts 2000) constructed from historical hydrography. Donohue et al. (2015) reviews this methodology as applied to the GOM. The GEM tables extended from the surface to 3000 dbar. Geopotential at each PIES site was determined by integrating specific volume anomaly. Through optimal interpolation (OI; Bretherton et al. 1976), horizontal gradients of specific volume anomaly yielded mapped geostrophic velocity referenced to zero at the ocean bottom, nominally 3000 dbar. We term this field baroclinic referenced to the bottom or $b c b$.

As described in Donohue et al. (2010), the near-bottom pressure records were detided, dedrifted, and leveled. Here, leveled bottom pressures means bottom pressures that have been adjusted to the same absolute geopotential surface, nominally 3000 dbar. Simultaneous OI mapping of deep currents and pressure were used to provide a 3000 dbar reference velocity for the $b c b$ geostrophic velocities. We term the deep 3000 dbar field reference or $r e f$.

Absolute SSH was determined with PIES by combining a reference level sea surface height $\left(\mathrm{SSH}_{r e f}\right)$, leveled 3000-dbar pressures converted to height (pressure divided by gravity and density), with baroclinic SSH referenced to the bottom $\left(\mathrm{SSH}_{b c b}\right)$, surface geopotentials referenced to 3000 dbar converted to height (geopotential divided by gravity). This methodology is well established (e.g., Baker-Yeboah et al. 2009; Park et al. 2012). Estimated PIES SSH error is $5.7 \mathrm{~cm}$ (Donohue et al., 2015). In this work, we use absolute $\mathrm{SSH}$ for the model comparisons. While the $\mathrm{SSH}_{r e f}$ has important dynamic contributions, for the DynLoop PIES sites the variance of the SSH signal is 
dominated by $\mathrm{SSH}_{b c b}: 98 \%$ of the total $\mathrm{SSH}$ variance and $96 \%$ of mesoscale band (100-3 day) $\mathrm{SSH}$ variance is due to variance in $\mathrm{SSH}_{b c b}$.

The DynLoop array provides daily maps of temperature, density, sea surface height, and geostrophic velocity at mesoscale resolution. A thorough validation of the PIES methodology is provided in Hamilton et al. (2014) and Donohue et al. (2015). Here, we note that within the thermocline, the PIES captured more than $95 \%$ of the temperature variance, and RMS differences were small relative to signal size. Velocity comparisons within the thermocline revealed RMS differences less than $0.10 \mathrm{~m} \mathrm{~s}^{-1}$.

The Colorado Center for Astrodynamics Research (CCAR) objectively mapped historical mesoscale altimeter data reanalysis product (Leben et al., 2002) was used to determine the position of the LC in the Gulf. The satellite altimeter data available for the historical reanalysis during the observational program included Jason-1, Envisat, and OSTM/Jason-2 satellite altimeters. Jason-1 tandem mission was operating during the program. Envisat transitioned from its nominal 35-day repeat orbit to a 30-day repeat orbit on 22 October 2010. A detailed description of the processing of the GOM SSH dataset can be found in Hamilton et al. (2014). Separation of LCEs from the LC was identified by the breaking of the 17-cm SSH contour in the CCAR GOM historical SSH data product. In this product, the 17-cm SSH contour closely tracks the LC (Leben, 2005).

\subsection{Model}

This study evaluates outputs from the data-assimilative GOM HYCOM expt_31.0. This particular model has $\sim 4 \mathrm{~km}$ horizontal grid spacing at the latitude of the $\operatorname{GOM}\left(1 / 25^{\circ}\right)$ and uses 20 vertical coordinate surfaces. The 
model uses a hybrid vertical layering system, employing isopycnal layers in the stratified open ocean, bottom-following $\sigma$-coordinates in coastal areas, and fixed pressure-coordinates in the mixed layer (Bleck, 2002). Interface depths change at each time step to reflect thermohaline variability, and layers are more closely spaced in the upper ocean. Outputs are interpolated to a nominal latitude-longitude-depth grid and archived in NetCDF format. The model is run in near real time at the NAVOCEANO Major Shared Resource Center to produce seven-day forecasts and four-day hindcasts. Here, analysis is performed on archived hindcast data spanning 15 May 2009 to 23 October 2011. This range was chosen to encompass available model output during a unified period of high data return from mooring instruments. Hourly hindcast data are publicly available on the HYCOM consoritum data server (http://hycom.org/dataserver). For a detailed description of the model and its outputs, the reader is referred to http://hycom.org/data/goml0pt04/expt31pt0. For a detailed description of HYCOM, the reader is referred to Bleck (2002), Chassignet et al. (2003), and Chassignet et al. (2006).

HYCOM31.0 uses the 3D-VAR Navy Coupled Ocean Data Assimilation (NCODA) system (Cummings, 2005; Cummings and Smedstad, 2013). NCODA assimilates all available observations. These include surface information from satellites (SST and SSH), plus in situ temperature and salinity profiles from XBTs (expendable bathythermographs), CTDs (conductivitytemperature-depth), gliders, and Argo floats (Chassignet et al., 2007, 2009; Cummings and Smedstad, 2013; Metzger et al., 2014). Satellite altimetry for NCODA comes from the NAVOCEANO Altimeter Data Fusion Center, which combines SSH from Jason-1, OSTM/Jason-2, Geosat, and Envisat. 
Vertical projection of the surface observations is achieved via generation of synthetic profiles using the Modular Ocean Data Analysis System (MODAS; Fox et al. 2002).

Midnight snapshots were used for this study: 00z model hindcasts were compiled into time series and low-passed with a 72 -hour $4^{\text {th }}$ order low-pass Butterworth filter. This filtering paralleled the treatment of the DynLoop observations. Modeled temperature and velocity at the grid points closest to mooring sites were used in site-to-site comparisons of temperature and velocity between tall moorings and HYCOM31.0. Differences between mooring locations and nearest model grid point were less than $2.2 \mathrm{~km}$. Tall moorings experienced "blow-down" or "draw-down" during time periods of strong currents. This drew instrumentation below its nominal depth. Therefore, measurement depth $p(t)$ varied with time. For point comparisons, model temperature and velocity were also vertically interpolated to $p(t)$ for each moored sensor. If a companion pressure measurement did not exist for a current meter or temperature sensor, $p(t)$ was constructed by linear interpolation of pressure records above and below the sensor.

Following Dukhovskoy et al. (2015) and Leben (2005), the position of the modeled LC is also tracked using the $17-\mathrm{cm}$ contour in the demeaned SSH fields. Note that in this work, the SSH contours are used qualitatively to place statistical quantities, such as eddy kinetic energy and SSH variance, into the context of the LC position.

\subsection{Methodology}

Taylor diagrams display the simultaneous comparison of multiple time series (Taylor, 2001). In the Taylor diagram representation, comparisons are 
made to a "reference" time series. Here, the reference time series are the observations: to compare $900 \mathrm{~m}$ temperature at mooring a1, for example, the observational time series at this location and depth is used as a reference for comparison with the modeled equivalent. A comparison at one depth and location yields a single point on the Taylor diagram indicating correlation coefficient and root-mean-squared difference (RMSD) between the modeled and observed time series, as well as the ratio of their standard deviations $\left(\sigma_{\text {hyc }} / \sigma_{o b s}\right)$. Hence, the ideal comparison has a correlation of 1.0, zero RMSD, and $\sigma_{h y c} / \sigma_{o b s}=1.0$. Note that RMSD is normalized by the standard deviation of the reference series, and that this normalized value will be referred to herein simply as RMSD. Because the RMSD is normalized by standard deviation, its inverse is a proxy for signal-to-noise ratio. The ratio $\sigma_{\text {hyc }} / \sigma_{o b s}$ evaluates the relative magnitude of variance of a modeled time series compared to the corresponding observation (Taylor, 2001).

Array-mean model-to-observation coherence was calculated by averaging cross- and auto-spectral density functions over all PIES sites. If $P_{x y}$ is the cross-spectral density between HYCOM31.0 and PIES, and $P_{x x}$ and $P_{y y}$ are the power spectral densities of HYCOM31.0 and PIES measurements, respectively, at a single site, then the array-mean coherence is given by

$$
C_{a v g}=\frac{\left|\left\langle P_{x y}\right\rangle\right|^{2}}{\left\langle P_{x x}\right\rangle\left\langle P_{y y}\right\rangle}
$$

where \langle\rangle indicates the average over all sites. For this study, $P_{x x}, P_{y y}$, and $P_{x y}$ were calculated using Welch's method with a 128-day Hanning window and $50 \%$ overlap (see Bendat and Piersol 2000). Error is estimated by the 95\% confidence limit following Harris (1978) and Thompson (1979). 
Complex Empirical Orthogonal Functions (CEOF) of mapped PIES and HYCOM31.0 SSH fields were generated for each eddy event and for four frequency bands to quantify meander propagation. Here we followed the methodology of Barnett (1983), where the cross-covariance matrix for the EOF is derived from the scalar band-passed SSH fields and their Hilbert transform. The CEOF method yields a spatial amplitude and phase, as well as a temporal amplitude and phase. This differs from a complex vector EOF where, for example, the cross-covariance matrix for the EOF comes from the complex input time series $U=u+i v$ where $u$ and $v$ are zonal and meridional velocities. A review of EOF methods can be found in Hannachi et al. (2007). Following comparable analysis in Donohue et al. (2015), for each CEOF the spatial phase gradient, $\delta \phi / \delta s$ where $\phi$ is phase and $s$ is distance, is calculated for regions where the corresponding normalized CEOF spatial amplitude is greater than 0.5. Note that $\delta \phi / \delta s$ is the magnitude of the wavenumber. Propagation phase speed is then determined from

$$
c_{p}=\frac{\omega}{\delta \phi / \delta s}
$$

where $\omega$ is the central frequency of a given frequency band.

Model mapped stream function fields were generated by optimally interpolating HYCOM31.0 velocity fields using a process adapted from Bretherton et al. (1976), detailed in Watts et al. (1989, 2001), and applied to the DynLoop observations (Hamilton et al., 2014; Donohue et al., 2015, 2016). A correlation length scale of $50 \mathrm{~km}$ was used. 


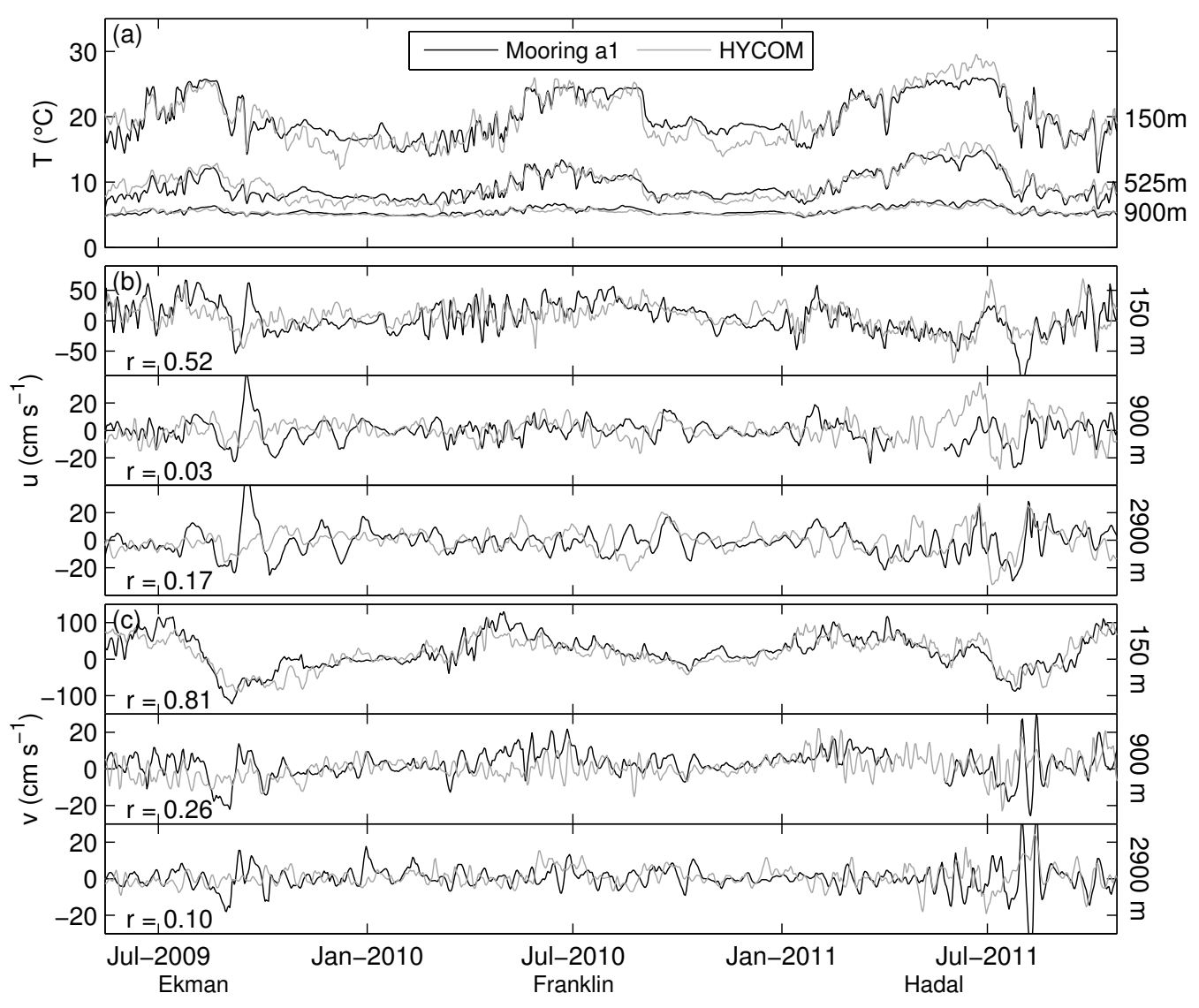

Figure 3: Time series of observed (black) and modeled (gray) (a) temperature, (b) zonal, and (c) meridional velocity. Nominal depths are noted along the right side of each panel. Correlation coefficients between observed and modeled velocity time series are given in the lower left corners. Temperature correlation coefficients are 0.88 for the 500 and $900 \mathrm{~m}$ depths and 0.82 for the $900 \mathrm{~m}$ record. Note that $y$-axis limits vary.

\section{Time-Series Point Comparisons}

Figure 3 shows time series of temperature, zonal, and meridional velocity at mooring a1. Visually, modeled upper ocean temperatures and $150 \mathrm{~m}$ velocity time series closely track their corresponding observed time series (Figure $3)$. Temperatures below the thermocline ( 900 $\mathrm{m}$ depth) are quite uniform, 
therefore temperature comparisons were restricted to the upper $900 \mathrm{~m}$ of the water column. Correlation coefficients cited in Figure 3 provide qualitative assessment of how well the two time series co-vary in time. Statistical significance of correlation coefficients are discussed below when presented in Taylor diagrams. Multiple time scales are evident in the temperature and $150 \mathrm{~m}$ velocity time series. There was a low-frequency ( $>300$ day) signal associated with the intrusion and retreat of the LC. In the mesoscale (3-100 day) band, relatively high-frequency oscillations, $\sim 3-20$ day, tended to occur in this record as the LC entered the array, for example in May/June 2010, followed by lower-frequency variability between 40-100 day. At depth, model and velocity time series do not consistently co-vary with one another (Figure 3b,c: $900 \mathrm{~m}$ and $2900 \mathrm{~m}$ ). Both model and observations showed increased deep variability during LCE separation events, however, this enhancement was more dramatic in the observations; for example, the strong pulses in October 2009 during Eddy Ekman's separation and August 2011 during Eddy Hadal's separation.

Figure 4a summarizes the point-to-point temperature statistics. Standard deviation ratios above the thermocline ( $600-900 \mathrm{~m}$ depth) were clustered near 1.0, indicative of comparable variance between model and observations, and ranged between 0.62 and 1.27. There is a tendency for model records deeper than $\sim 600 \mathrm{~m}$ depth to have reduced variance relative to observations. The majority of normalized RMSDs were below 0.5. This corresponds to signal-to-noise ratios above 1.0 for these points. Dimensional RMSD (Figure 5a) decreased with depth, with values near $1.5^{\circ} \mathrm{C}, 1.25^{\circ} \mathrm{C}, 0.7^{\circ} \mathrm{C}$, and $0.4^{\circ} \mathrm{C}$, at $75 \mathrm{~m}, 250 \mathrm{~m}, 600 \mathrm{~m}$, and $900 \mathrm{~m}$, respectively. Correlation coeffi- 

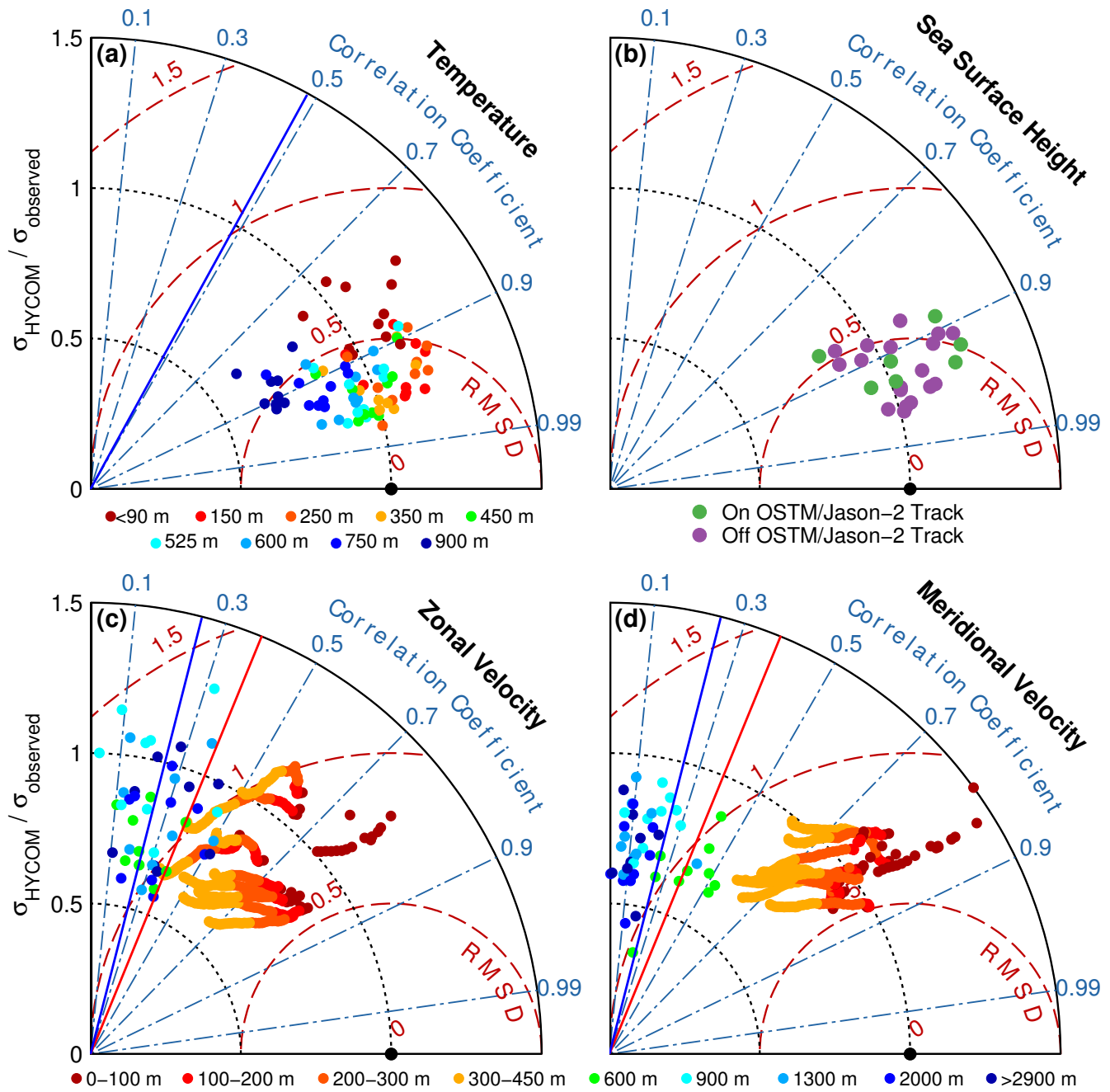

Figure 4: Taylor diagram of observation-to-model correlation (blue labeled axis), normalized RMS difference (red labeled axis), and standard-deviation ratio (black labeled axis) for (a) temperature, (b) SSH, (c) zonal velocity, and (d) meridional velocity comparisons. Time series depths are denoted by color scaling: a key is provided below panels c, $\mathrm{d}$ for velocity and below panel a for temperature. The black dot in each panel indicates the reference point. Green (purple) filled circles in panel d indicate PIES sites co-located (not co-located) with OSTM/Jason-2 altimeter tracks. Red and blue lines in panels a,b indicate $95 \%$ statistical significance for the correlations above and below $900 \mathrm{~m}$, respectively, and blue line in c shows $95 \%$ significance for all temperature correlations. 

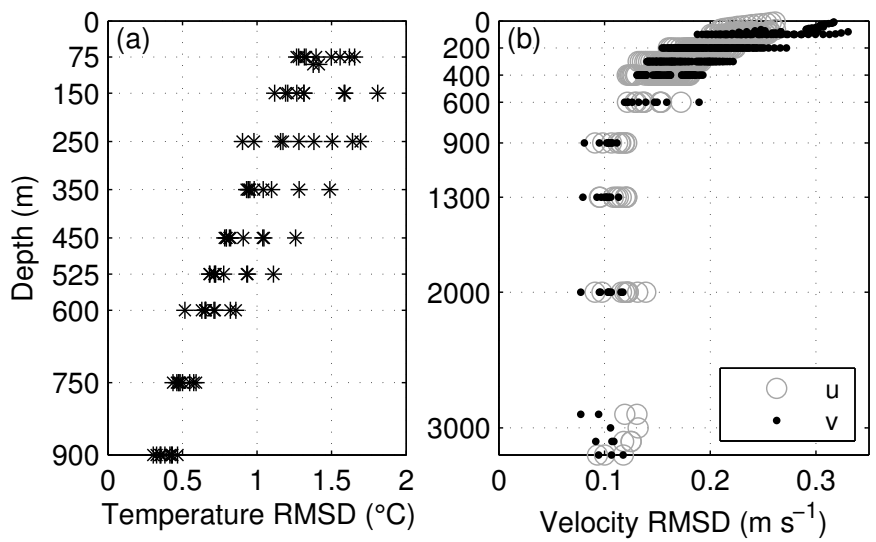

Figure 5: Dimensional RMSD versus depth for all (a) temperature and (b) zonal (gray circles) and meridional (black points) velocity. Note that $y$-axis scales differ between panels.

cients ranged from 0.75 to 0.98 for all moorings and depths, with an arrayaveraged correlation of 0.92 , indicating that modeled and observed temperatures had a similar pattern of variability. These correlations, interpreted in the context of a linear relationship, show that on average $85 \%$ of the common variance is explained by a linear fit. All correlations were statistically different from zero at the $95 \%$ confidence level. Degrees of freedom (DOF) were determined from autocorrelations of the measurements following the methodology discussed in Bendat and Piersol (2000). Average DOF for the temperature time series was near 15. All temperature correlations were greater than 0.482 , the criteria for $95 \%$ statistical significance.

Similar to the upper-ocean temperature comparisons, model and PIES SSH agree well with one another in that standard deviation ratios were near one, the majority of the normalized RMSD were less than 0.5 , and correlation coefficients were above 0.84 (Figure $4 \mathrm{~b}$ ). Standard deviation ratios ranged from 0.82 to 1.26 with a mean of 1.03. All comparisons resulted in 
normalized RMSD lower than 0.58 with a minimum of 0.26 , corresponding to a dimensional RMSD range of $7-14 \mathrm{~cm}$. Correlation coefficients ranged between 0.84 and 0.97 , with mean value of 0.93. DOF for SSH were near 15. Hence, all SSH comparisons were statistically significant at the $95 \%$ level $(r>0.482)$. Modeled SSH explains nearly $87 \%$ of the observed signal. No distinction in statistics were found for sites on or off the OSTM/Jason-2 altimeter ground tracks. Our interpretation of this result is that, in general, high correlation coefficients occurred at points with high variance, and most of the variance derived from low-frequency variability associated with the LC intrusion and retreat cycles.

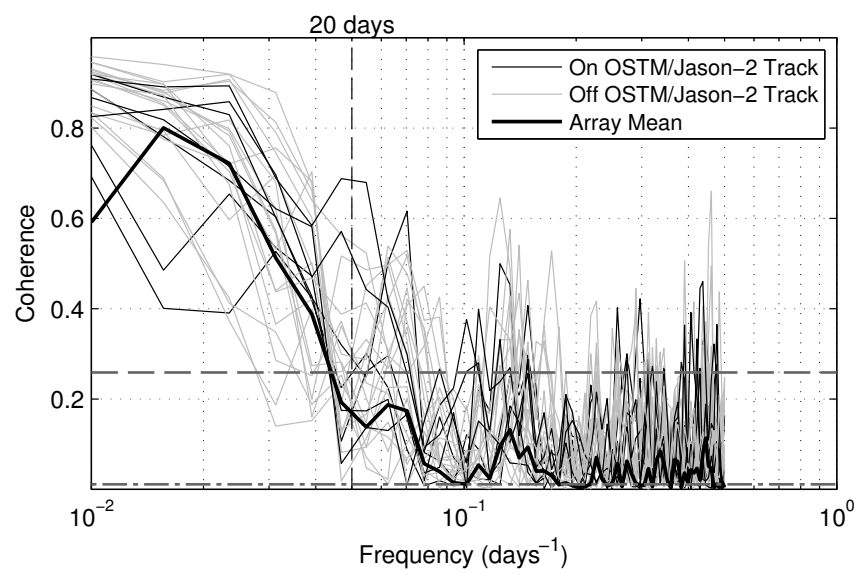

Figure 6: Site-to-site (thin lines) and array-mean (thick line) mean-squared SSH coherence between HYCOM31.0 and PIES. 95\% confidence limits for individual sites (horizontal dashed line) and array-mean (horizontal dash-dot line) give estimates of significance. Coherence drops around $1 / 20$ days $^{-1}$ (vertical dashed line), near the Nyquist frequency of the Jason-1 and OSTM/Jason-2 altimetry satellites. PIES co-located (not co-located) with OSTM/Jason-2 altimeter ground tracks are denoted by black (gray) thin lines.

360 Comparisons between observed and modeled velocity showed mixed re- 
sults with a marked distinction between upper and deep levels in both RMSD and correlations (Figure 4c,d). Model-to-observation standard deviation ratios, $\sigma_{\text {hyc }} / \sigma_{\text {ref }}$, were below 1.0 for $79 \%$ of all velocity comparisons ( $81 \%$ for zonal, $76 \%$ for meridional) indicating lower velocity variance in the model than observations. This was especially so for depths greater than $900 \mathrm{~m}$ : $88 \%$ of comparisons yielded ratios below 1.0. On average, modeled variance was $77 \%$ that of observations ( $65 \%$ below $900 \mathrm{~m}$ ). Normalized RMSD were between 0.5 and 1.0 for depths less than $450 \mathrm{~m}$. Signal to noise ratio decreased with depth, as evidenced by the increase in RMSD to values greater than 1.0 for the majority of velocity comparisons below $600 \mathrm{~m}$. Dimensional RMSD are shown in Figure 5b: RMSD was greatest in the upper water column with a maximum of $0.33 \mathrm{~m} \mathrm{~s}^{-1}$ at $80 \mathrm{~m}$, and decreased with depth to below 0.14 $\mathrm{m} \mathrm{s}^{-1}$ deeper than $900 \mathrm{~m}$ and to $\sim 0.1 \mathrm{~m} \mathrm{~s}^{-1}$ around $3000 \mathrm{~m}$ depth. Above $900 \mathrm{~m}$, mean correlations ranged between 0.62 and 0.74. Average DOF for velocity time series varied with depth, reflecting the larger contribution of low-frequency variability in the upper-ocean spectra. In the upper-ocean, for depths above $900 \mathrm{~m}$, DOF were near 25, hence, correlations greater than 0.381 were significant at the $95 \%$ level. We note that although correlations in the upper $900 \mathrm{~m}$ were statistically significant, the variance explained is low, ranging from 38-55\%. Below $900 \mathrm{~m}$ depth, mean correlations were low: 0.30 and 0.12 for zonal and meridional velocity, respectively. At $900 \mathrm{~m}$ and below, DOF were near 60 , with 0.250 as the criteria for $95 \%$ statistical significance. Again, while a handful of sites had correlations statistically different than zero, the explained variance is low. Curiously, there were differences between zonal and meridional comparison statistics. For depths greater than 
$500 \mathrm{~m}$, zonal velocity correlation coefficients, RMSD, standard deviation ratios indicated better overall agreement with observations than for meridional velocities. The reasons for this are not well understood at this time.

To investigate the agreement between model and observations as a function of frequency, mean-squared coherence between HYCOM31.0 and PIES SSH was calculated. At all PIES sites, coherence decreased as frequency increased (Figure 6). Many of the individual site-to-site coherences fell below the $95 \%$ confidence limit near a frequency of $1 / 20$ days $^{-1}$. Array-mean coherence also fell sharply at this frequency, which corresponds to the Nyquist frequency of the Jason-1 and OSTM/Jason-2 altimetry missions that provided data assimilated by HYCOM31.0. Note that the variability for frequencies higher than $1 / 20$ days $^{-1}$ represented a small fraction, $<2 \%$, of the total variability, and only $\sim 8 \%$ of the variance for mesoscale frequencies (100-3 day). While there was a sharp decrease in coherence below $1 / 20 \mathrm{~d}^{-1}$, statistically significant coherence did exist at some sites for the high frequencies. We explore the spatial distribution of SSH variance further in section 4.1.

Point-to-point comparisons are demanding: a model may correctly simulate circulation features, but a spatial or temporal offset from observations could spoil the point-to-point comparison. Moreover, point-to-point comparisons offer limited insight into how well a model simulates a specific oceanic process. Taking this into consideration, the remainder of this paper focuses on broad-scale and feature-based comparison. 

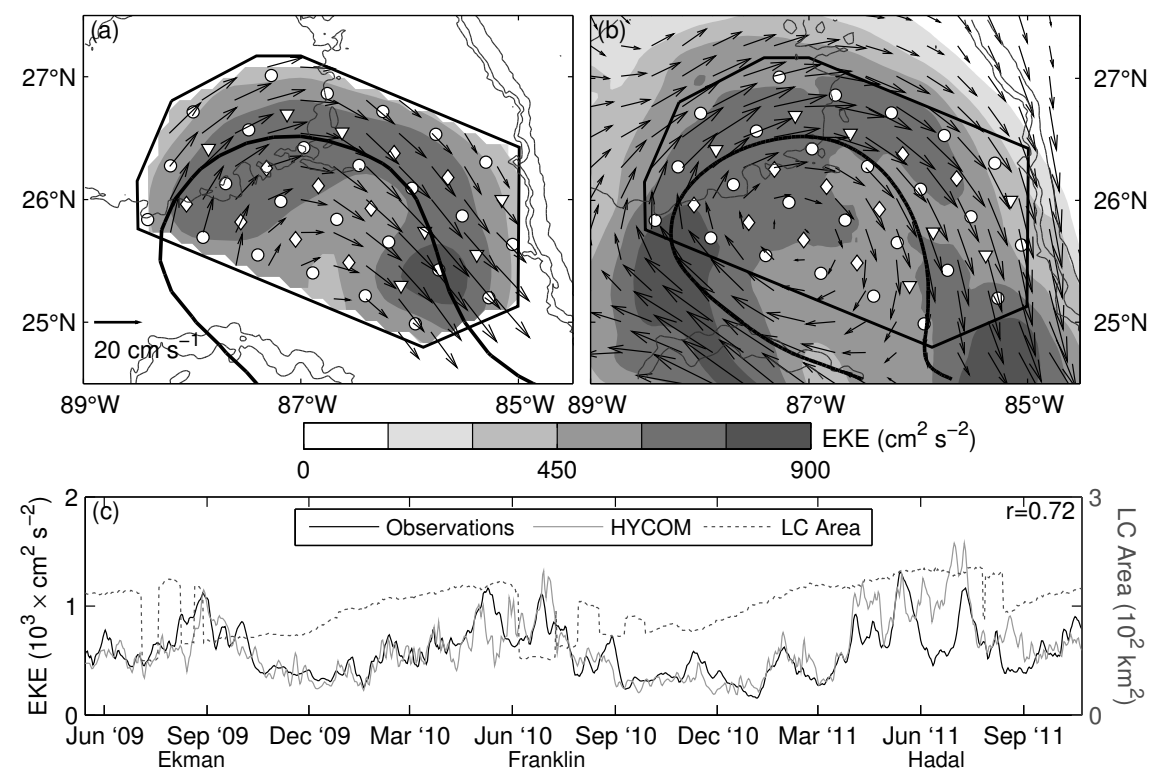

Figure 7: Time-averaged (a) observed and (b) modeled eddy kinetic energy (EKE; shading) at $200 \mathrm{~m}$ depth, with time-mean velocity vectors superimposed. PIES (circles), tallmooring (diamonds), and near-bottom mooring (triangles) locations are plotted along with bathymetry contoured at 1000, 2000, $3000 \mathrm{~m}$ depth (thin contours) and mean Loop Current position (thick black curve). (c) Time series of array-mean observed (black) and HYCOM31.0 (solid gray) $200 \mathrm{~m}$ EKE averaged over the same region, and LC area (dashed) from the CCAR SSH product.

\section{Broad-Scale Spatial Patterns}

In the upper ocean, observed and modeled EKE exhibit similar spatial structure and strength. Observed and modeled EKE at $200 \mathrm{~m}$ depth is shown in Figure 7. Both fields exhibit bands of high EKE along the mean path of the LC. Amplitudes of array-averaged $200 \mathrm{~m}$ EKE from mapped PIES and HYCOM31.0 were comparable, with time-mean values of $\sim 580 \mathrm{~cm}^{2} \mathrm{~s}^{-2}$ and $\sim 600 \mathrm{~cm}^{2} \mathrm{~s}^{-2}$, respectively. Time series of observed and modeled arrayaveraged EKE matched well (Figure 7c): peaks occurred together during time periods when the $\mathrm{LC}$ is positioned within the array; the correlation 


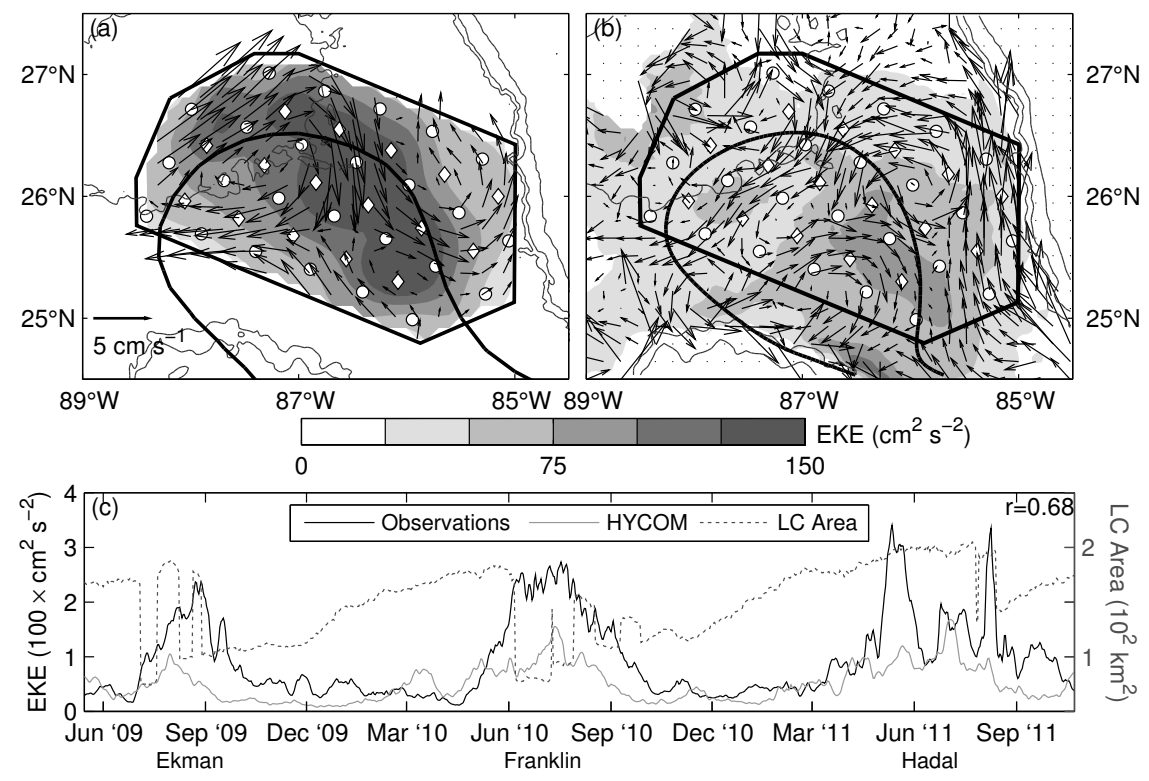

Figure 8: Same as Figure 7, but for $2500 \mathrm{~m}$ depth.

between the series is 0.72 .

A time series of modeled array-averaged deep (2500 m) EKE shows peaks consistent with observations prior to and during eddy separations, but with roughly half $(53 \%)$ the observed amplitude (Figure 8c). Correlation between the two array-averaged time series was 0.68. Spatial patterns of EKE agree in the sense that both model and observations showed enhanced deep eddy variability in the eastern portion of the array, but these maps showed again that modeled deep EKE was approximately half that of observations (Figure 8a,b). Note that the mean fields both showed deep mean anticyclonic circulation in the northwestern array, and a deep cyclone in the northeast corner. The model, however, showed features that were not present in observations: a deep northern flow just offshore of the West Florida Shelf, and a deep anticyclone in the southern array. 

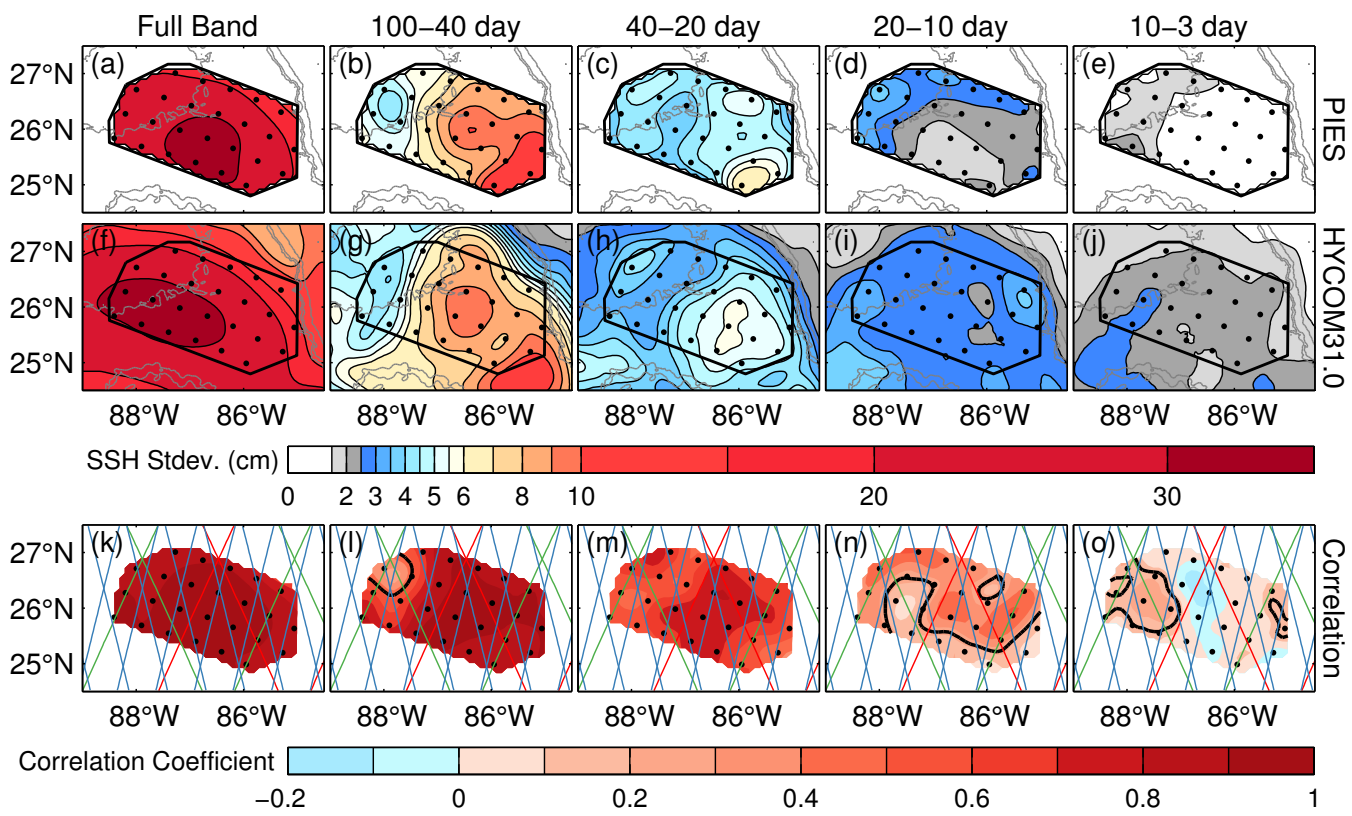

Figure 9: Standard deviation of PIES (top row) and HYCOM31.0 (middle row) bandpassed SSH, with increasing band frequency from left to right. Black dots show PIES locations. Similar magnitudes and patterns of variance are seen between datasets. Bottom panels map the correlation coefficient between the two series. Satellite altimeter tracks are also plotted on each map: OSTM/Jason-2 (green), Jason-1 Tandem Mission (red), and ERS (blue). Black contours in the bottom row indicate statistical significance at the $95 \%$ confidence level for each band.

\subsection{Sea Surface Height Variance in Frequency Space}

SSH variance was dominated by the intrusion and retreat of the LC associated with the LCE cycle (Figure 9a,f). Periodicities longer than 100 days accounted for $\sim 80 \%$ of the SSH variance. Liu and Weisberg (2012) determined the peak-to-peak amplitude of the seasonal steric signal to be near $12 \mathrm{~cm}$, which in terms of standard deviation is $4.2 \mathrm{~cm}$. Therefore, a small portion, between $2-5 \%\left(4.2^{2} / 30^{2}-4.2^{2} / 20^{2}\right)$ of this variance is due to the seasonal steric signal. Shorter-period mesoscale (100-3 day) meanders play an important role in LCE dynamics. To investigate spatial patterns as a 
function of frequency, SSH fields were band-passed into four frequency bands. Cut-off frequencies for the bands followed Donohue et al. (2015) and were based upon peaks in array-measured SSH spectra near 1/60,1/30, and 1/15 $\mathrm{d}^{-1}$. The four bands include two low-frequency bands corresponding to periods of 100-40 and 40-20 days, and two high-frequency bands with periods of 20-10 and 10-3 days. The mesoscale band, 100-3 days, represented $12 \%$ and $13 \%$ of modeled and observed total SSH variance, respectively, within the mapping array. In the mesoscale band and within the mapping array, modeled variance was distributed as follows: $64 \%, 22 \%, 9 \%$, and $5 \%$ of variance in the 100-40, 40-20, 20-10, and 10-3 day bands, respectively. This is compared to $70 \%, 21 \%, 6 \%$, and $2 \%$ for observations. Note that Donohue et al. (2015) assessed bottom-referenced baroclinic SSH $\left(\mathrm{SSH}_{b c b}\right)$, rather than total SSH, hence percent variance cited here differ slightly for observations. Maps of standard deviation of band-passed HYCOM31.0 SSH fields (Figure $9 g-j$ ) revealed similar spatial distributions of variance to those found by Donohue et al. (2015) (Figure 9b-e). In the two low-frequency bands, variance was highest along the eastern and southeastern sides of the array, while in contrast, the two high-frequency bands had elevated variance along the north-northwest portion of the array. In the mesoscale band, meanders along the LC path, including adjacent frontal eddies, were responsible for the variance distribution. The CEOF analysis of Donohue et al. (2015) was repeated using modeled and observed SSH fields to document wavelengths and phase speeds associated with these spatial patterns (see Section 5.1).

The bottom panels of Figure 9 show correlation between observed and HYCOM31.0 SSH. As expected from Figure 6, correlations decreased as fre- 
quency increased, with marginally significant correlations for the highest frequency band. In the full band and 40-20 day band, correlations at 100\% of the points were significant at the $95 \%$ confidence level; $93 \%, 67 \%$, and $22 \%$ of points in the 100-40, 20-10, and 10-3 day bands, respectively, had significant correlation. For reference, correlations greater than 0.482, 0.468, $0.330,0.236$, and 0.140 were significant for the full band, 100-40, 40-20, 20 10, and 10-3 day bands, respectively. In each frequency band, regions of high variance and high correlations were co-located. No obvious relationship between satellite tracks and correlation was found.

\section{Phenomenological Comparisons}

\subsection{LC Meander Characteristics}

To investigate the propagation characteristics of LC meanders, CEOFS were determined from observed and modeled SSH for four time periods when the LC was positioned within the DynLoop array and for the four frequency bands used to partition the mesoscale variance in Figure 9. We term the time periods by the LCE event: Ekman May 1 - September 1, 2009; Franklin February 1 - September 1, 2010; Hadal May 1 - August 1, 2011; and Icarus September 1 -October 23, 2011. For these CEOFs, we considered only the first CEOF mode. Variance explained by the first mode exceeded twice the variance explained by the second mode, with one exception for the observations: Ekman 20-10 day band; and four exceptions for the model: Ekman, Franklin, Hadal 20-10 day band, and Icarus 10-3 day band (Table 1). Spatial amplitude and phase are shown in Figures 10 through 13. Note that this was a slightly different analysis than Donohue et al. (2015), where bottom- 
Table 1: Percentage of total CEOF variance explained by the first and second mode for each eddy event and frequency band from CEOFs of PIES and HYCOM sea surface height fields.

\begin{tabular}{c|ccc}
\hline \hline & $\begin{array}{c}\text { Band } \\
\text { (days) }\end{array}$ & $\begin{array}{c}\text { PIES } \\
\text { (Mode Variance) } \\
\text { Mode-1/ Mode-2 }\end{array}$ & $\begin{array}{c}\text { HYCOM31.0 } \\
\text { (Mode Variance) } \\
\text { Mode-1/ Mode-2 }\end{array}$ \\
\hline Ekman & $100-40$ & $89.2 \% / 9.60 \%$ & $87.6 \% / 9.6 \%$ \\
04 May 2009-01 Sep. 2009 & $40-20$ & $62.6 \% / 30.0 \%$ & $63.5 \% / 30.0 \%$ \\
& $20-10$ & $48.8 \% / 28.9 \%$ & $56.3 \% / 28.9 \%$ \\
& $10-3$ & $69.0 \% / 12.8 \%$ & $41.5 \% / 12.8 \%$ \\
\hline Franklin & $100-40$ & $79.6 \% / 14.6 \%$ & $70.0 \% / 14.6 \%$ \\
01 Feb. 2010-01 Sep. 2010 & $40-20$ & $57.2 \% / 21.4 \%$ & $57.1 \% / 21.4 \%$ \\
& $20-10$ & $53.5 \% / 21.1 \%$ & $32.9 \% / 21.1 \%$ \\
01 Mar. 2011-01 Aug. 2011 & $10-3$ & $54.9 \% / 14.5 \%$ & $39.6 \% / 14.5 \%$ \\
\hline Hcarus & $100-40$ & $85.3 \% / 12.5 \%$ & $83.6 \% / 12.5 \%$ \\
01 Sep. 2011 - 23 Oct. 2011 & $20-10$ & $65.9 \% / 21.3 \%$ & $72.7 \% / 21.3 \%$ \\
\hline \hline
\end{tabular}

reference baroclinic SSH was used rather than total SSH. Nevertheless, the overall patterns and phase speeds were similar: phase speeds from Donohue et al. (2015) ranged from 8 to $50 \mathrm{~km} \mathrm{day}^{-1}$ and those presented here using total SSH spanned a range of 8 to $51 \mathrm{~km} \mathrm{day}^{-1}$.

Modeled and observed CEOF spatial patterns in the low frequency bands (100-40 and 40-20 day) shared the following characteristics. In the 100-40 day band (Figures 10-12; panels a-d), spatial amplitudes were high along the eastern side of the LC; propagation was clockwise. In the 40-20 day band (Figures 10-12; panels e-h), modeled and observed CEOF spatial peaks appear in similar regions of the array, with clockwise propagation along the LC. 
For these low frequency bands, the DOF are low. For this reason, we do not show Icarus $100-40$ or 40-20 day band CEOFs. Note that, while the degrees of freedom are limited within each time period, the wavenumber/phase speed estimates from the three LCEs each provide independent estimates.
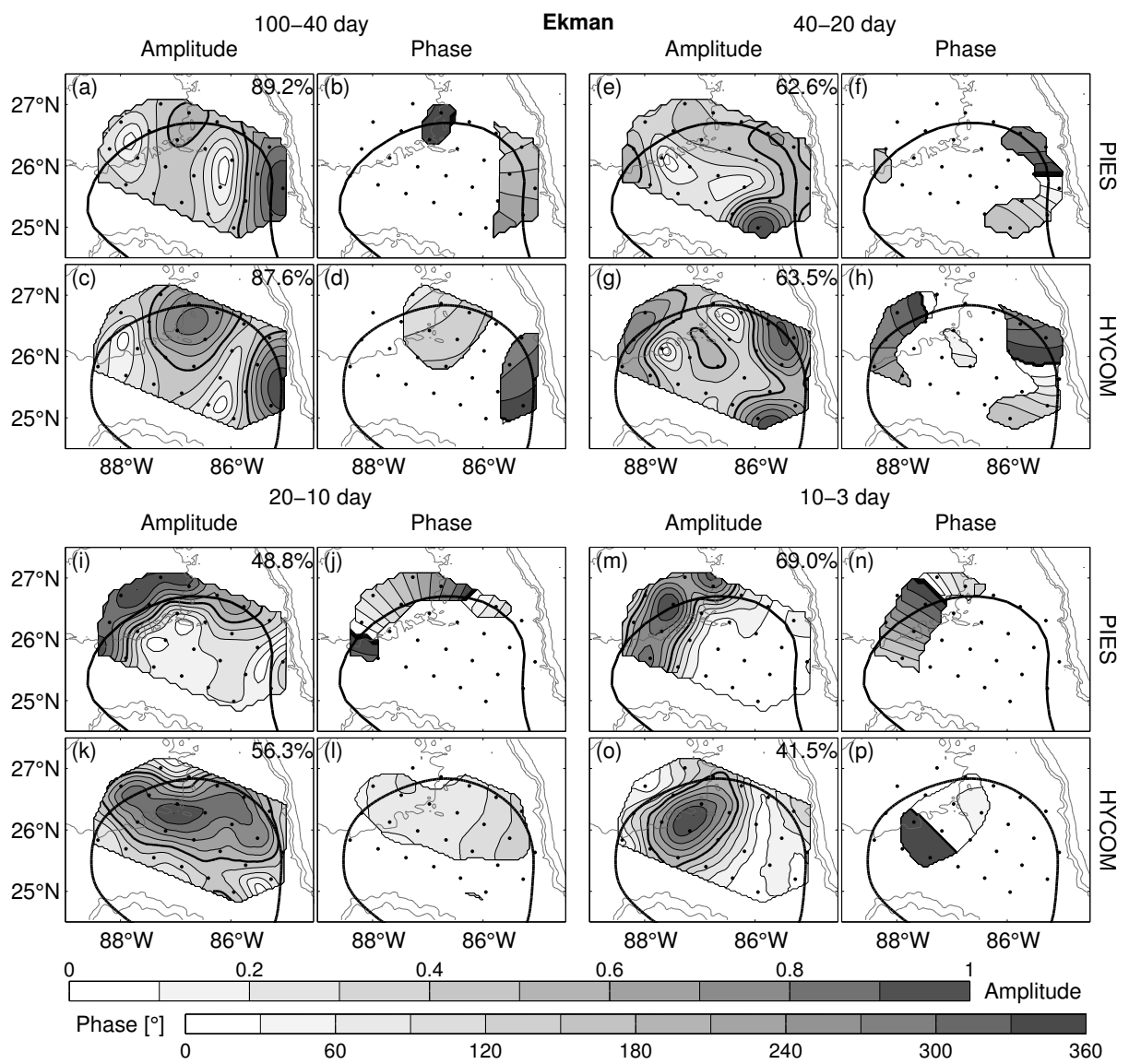

Figure 10: First-mode SSH CEOFs for the Ekman time period by frequency band. Bands are labeled at the top of each four-panel band-group. Normalized CEOF amplitude is presented in the left panels of each group, and phase (in degrees) in the right panels. PIES and model results are shown in the upper and lower panels of each group, respectively. For all panels: Bathymetry (gray contours; $1000 \mathrm{~m}$ intervals), PIES locations (black dots), and mean Loop Current position (thick black line) are included. Percentage of total variance explained by the first mode is indicated in the upper-right of each amplitude plot. 
For the high-frequency bands (20-10 and 10-3 day; Figures 10-12 i-p \& 13 $\mathrm{a}-\mathrm{h}$ ), the model and observations differed from one another. This discrepancy was most notable for Eddy Ekman (Figure 10), where high spatial amplitudes in observations were confined to the northwestern portion of the array along the LC mean path, while the modeled peak was displaced slightly inward of the LC path. However, both model and observations show that these highfrequency meanders were strongest along the northeast portion of the array, except for Eddy Hadal, where the LC was located noticeably more to the
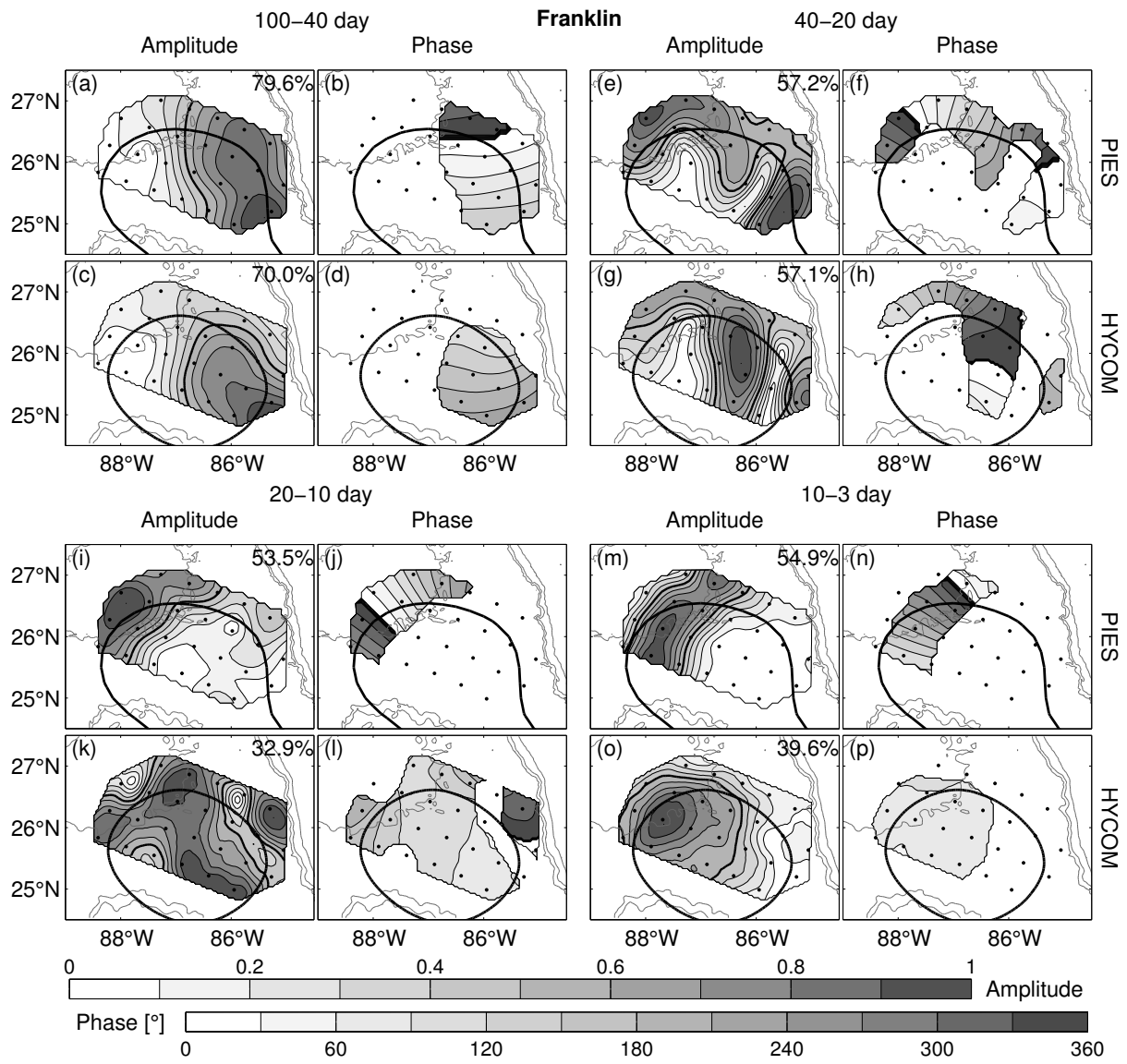

Figure 11: Same as Figure 10, but for Eddy Franklin. 

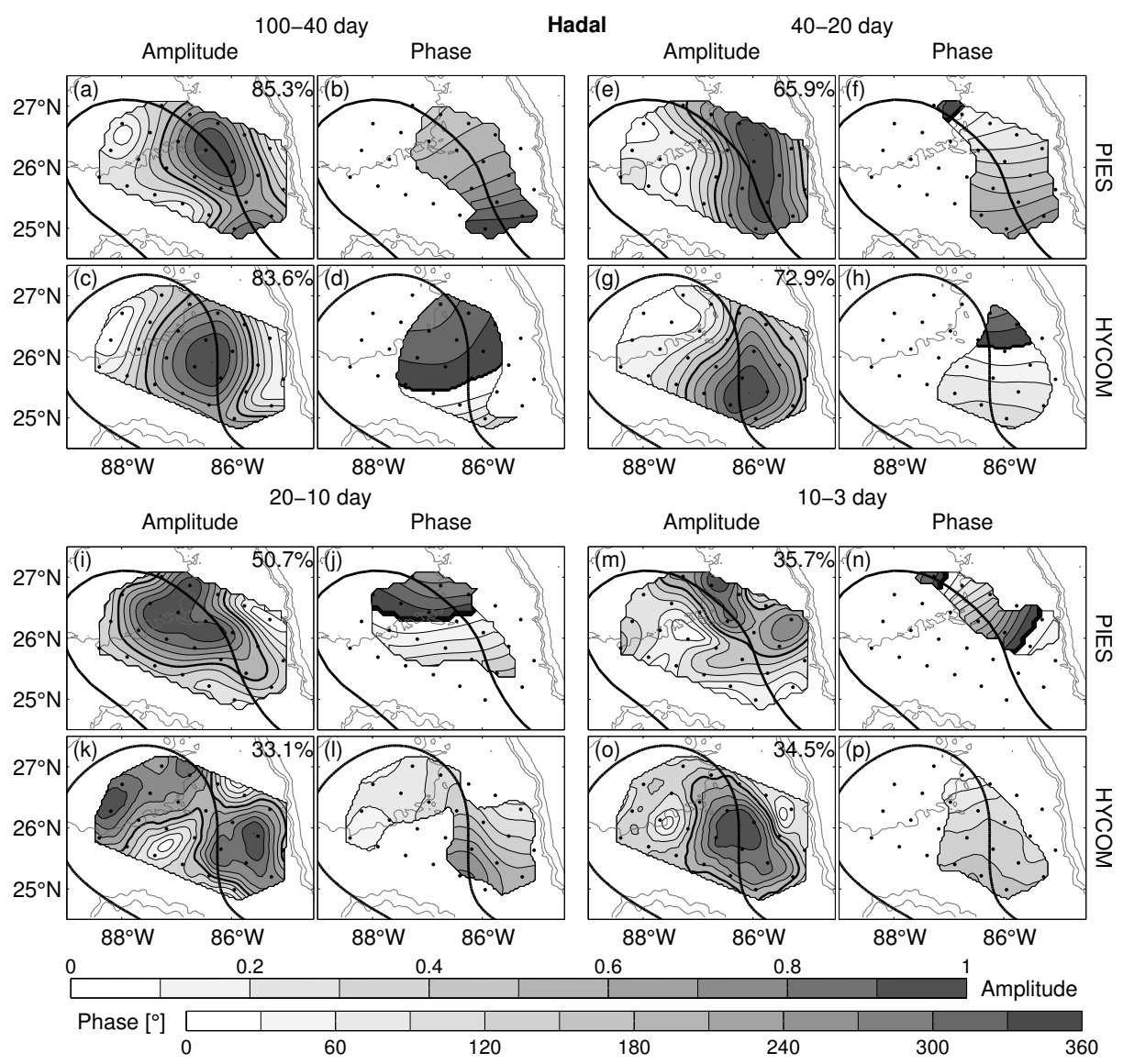

Figure 12: Same as Figure 10, but for Eddy Hadal.

west than during other eddy events and high-frequency meanders were found along the eastern LC path. Propagation in the high-frequency bands was clockwise for all eddy events, yet the phase gradient differed between model and observations. Overall, the model showed little change in spatial phase, indicating fast propagation. This was most apparent for eddies Ekman and Franklin.

To quantify propagation patterns seen in COEFs, phase speed and wavenumber were calculated from CEOF phase fields (see Section 2.3) for each com- 


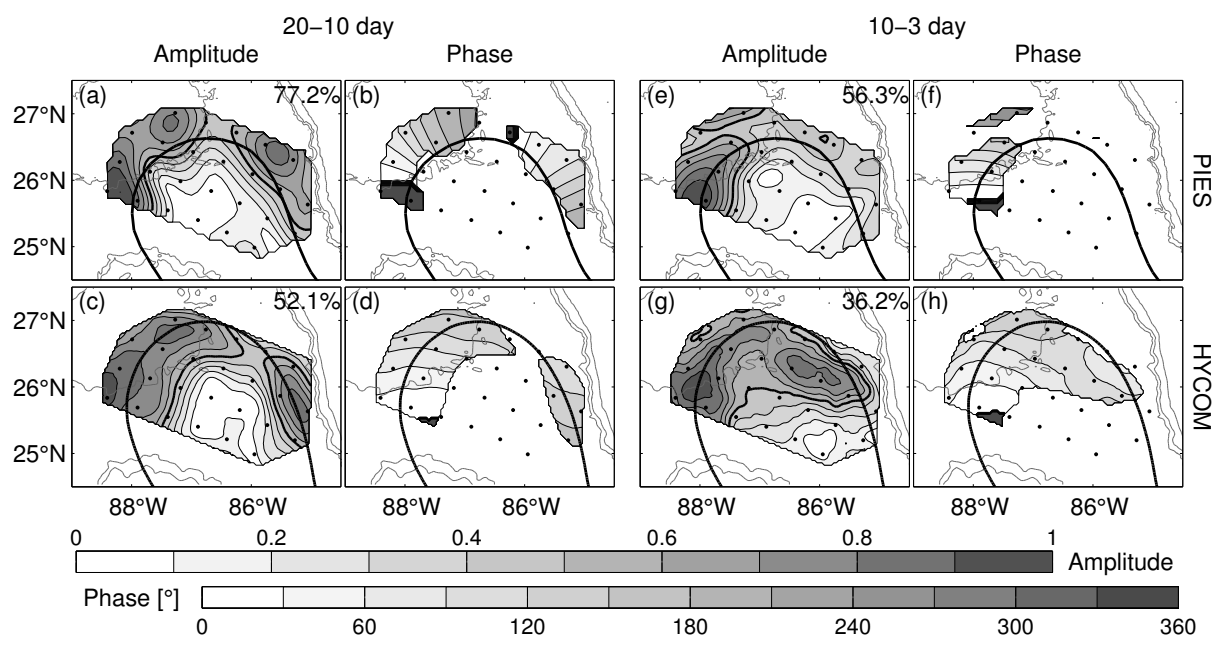

Figure 13: Same as Figure 10, but for Eddy Icarus in the 20-10 and 10-3 day bands only.

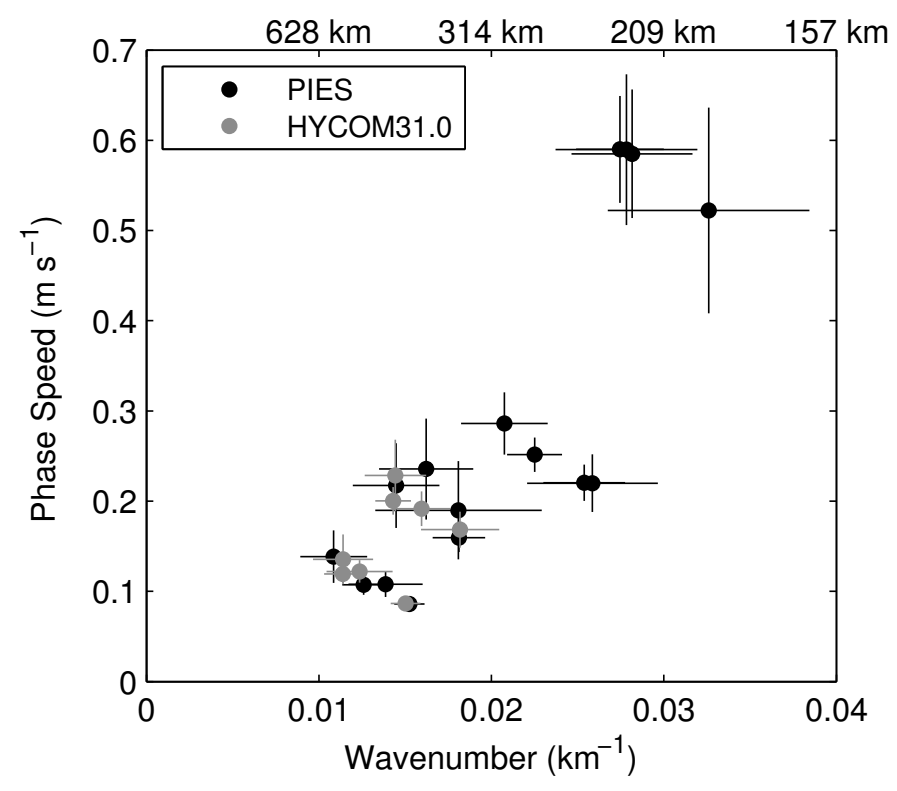

Figure 14: Phase speed vs. wavenumber estimates from HYCOM31.0 (gray) and PIES (black) SSH CEOFs. Error bars are standard error. Groupings from bottom to top correspond to 100-40, 40-20, 20-10, and 10-3 day frequency bands. 
bination of eddy and frequency band (Figure 14 and Table 2). As band frequency increased, phase speeds increased and wavelengths decreased. Mean phase speeds are within $8 \%$ and $2 \%$ of each other for the 100-40 and 4020 day band, respectively, indicating good agreement. On the other hand, HYCOM31.0 CEOF phase speeds for the two high-frequency bands were unrealistically large (see Table 2), and therefore not included in Figure 14.

In order to investigate whether data assimilation played a role in the discrepancies observed between HYCOM31.0 and DynLoop results at high frequencies (20-3 day band), a non data-assimilative (free running) HYCOM

Table 2: Loop Current meander phase speed $\left(c_{p}\right)$, wavenumber $(k)$, and wavelength $(\lambda)$ for each combination of eddy (first column) and band (second column) derived from SSH CEOF phase fields from PIES and HYCOM31.0. Italicized values were considered unreasonable and not included in Figure 14.

\begin{tabular}{c|c|ccc|ccc}
\hline \hline & Band & \multicolumn{3}{|c|}{ PIES } & \multicolumn{3}{c}{ HYCOM31.0 } \\
& $\begin{array}{c}c_{p} \\
(\text { days })\end{array}$ & $\begin{array}{c}k \\
\left(\mathrm{~m} \mathrm{~s}^{-1}\right)\end{array}$ & $\begin{array}{c}\lambda \\
\left(10^{-2} \mathrm{~km}^{-1}\right)\end{array}$ & $\begin{array}{c}c_{p} \\
(\mathrm{~km})\end{array}$ & $\begin{array}{c}k \\
\left(\mathrm{~m} \mathrm{~s}^{-1}\right)\end{array}$ & $\begin{array}{c}\lambda \\
\left(10^{-2} \mathrm{~km}^{-1}\right)\end{array}$ & $(\mathrm{km})$ \\
\hline Ekman & $100-40$ & 0.11 & 1.26 & 498.9 & 0.12 & 1.14 & 551.6 \\
4 May - 1 Sep. & $40-20$ & 0.19 & 1.81 & 347.3 & 0.17 & 1.82 & 345.5 \\
2009 & $20-10$ & 0.22 & 2.59 & 243.0 & 0.84 & 0.80 & 782.6 \\
& $10-3$ & 0.58 & 2.82 & 223.2 & 2.51 & 0.78 & 803.1 \\
\hline Franklin & $100-40$ & 0.09 & 1.52 & 412.2 & 0.09 & 1.50 & 418.2 \\
1 Feb. - 1 Sep. & $40-20$ & 0.24 & 1.62 & 387.3 & 0.23 & 1.44 & 435.4 \\
2010 & $20-10$ & 0.22 & 2.54 & 247.5 & 0.93 & 1.06 & 592.1 \\
& $10-3$ & 0.59 & 2.75 & 228.8 & 5.15 & 0.48 & 1301.1 \\
\hline Hadal & $100-40$ & 0.11 & 1.39 & 453.2 & 0.12 & 1.24 & 508.5 \\
1 Mar. - 1 Aug. & $40-20$ & 0.16 & 1.81 & 346.8 & 0.20 & 1.43 & 439.4 \\
2011 & $20-10$ & 0.25 & 2.25 & 279.2 & 0.51 & 1.57 & 401.2 \\
& $10-3$ & 0.52 & 3.26 & 192.8 & 1.45 & 1.27 & 496.2 \\
\hline Icarus & $20-10$ & 0.29 & 2.08 & 302.8 & 0.43 & 1.43 & 439.9 \\
1 Sep. - 23 Oct. & $10-3$ & 0.59 & 2.78 & 225.8 & 1.31 & 1.61 & 391.3 \\
2011 & - & - & - & - & - & - & - \\
\hline \hline
\end{tabular}


Table 3: Same as Table 1, but for three eddy time periods from free-running expt_02.2.

\begin{tabular}{c|c|c}
\hline \hline & Band & $\begin{array}{c}\text { Mode Variance } \\
\text { Mode-1/ Mode-2 }\end{array}$ \\
\hline 1 Jan. - 15 Mar. & $100-40$ day & $77.5 \% / 20.3 \%$ \\
1957 & $40-20$ day & $63.2 \% / 26.7 \%$ \\
& $20-10$ day & $52.2 \% / 28.7 \%$ \\
$10-3$ day & $37.6 \% / 21.4 \%$ \\
\hline 1 May. - 1 Aug. & $100-40$ day & $71.8 \% / 25.2 \%$ \\
1957 & $40-20$ day & $70.2 \% / 22.1 \%$ \\
& 20-10 day & $41.1 \% / 27.9 \%$ \\
& $10-3$ day & $38.4 \% / 20.9 \%$ \\
\hline 1 Apr. - 15 Jul. & $100-40$ day & $84.6 \% / 12.6 \%$ \\
1958 & $40-20$ day & $64.0 \% / 24.6 \%$ \\
& $20-10$ day & $56.8 \% / 18.8 \%$ \\
& $10-3$ day & $34.3 \% / 18.7 \%$ \\
\hline \hline
\end{tabular}

configuration was examined. The free running model, HYCOM GOMl0.04 experiment 02.2, utilized the same horizontal resolution and number of hybrid vertical layers as HYCOM31.0 (see Dukhovskoy et al. (2015) for a detailed description). Three LCE eddy events were identified that resembled the DynLoop observational period. SSH CEOFs were calculated for each of the three eddies in the four frequency bands. These were used to compute phase speed and wavenumbers. The first mode CEOFs are shown in Figures 15 through 17, and Table 3 provides the variance explained by the first two CEOF modes in each band. Because of the large amplitude (high variance) signals occurring on the West Florida Shelf, the highest frequency (10-3 day) band CEOFs excluded model data east of $84^{\circ} \mathrm{W}$. Figures 15 through 17 share similar characteristics to what was observed in DynLoop during the three eddy events. Consistent with observations, there was a tendency for low-frequency (100-20 day) and high-frequency (20-10 day) meanders to be 


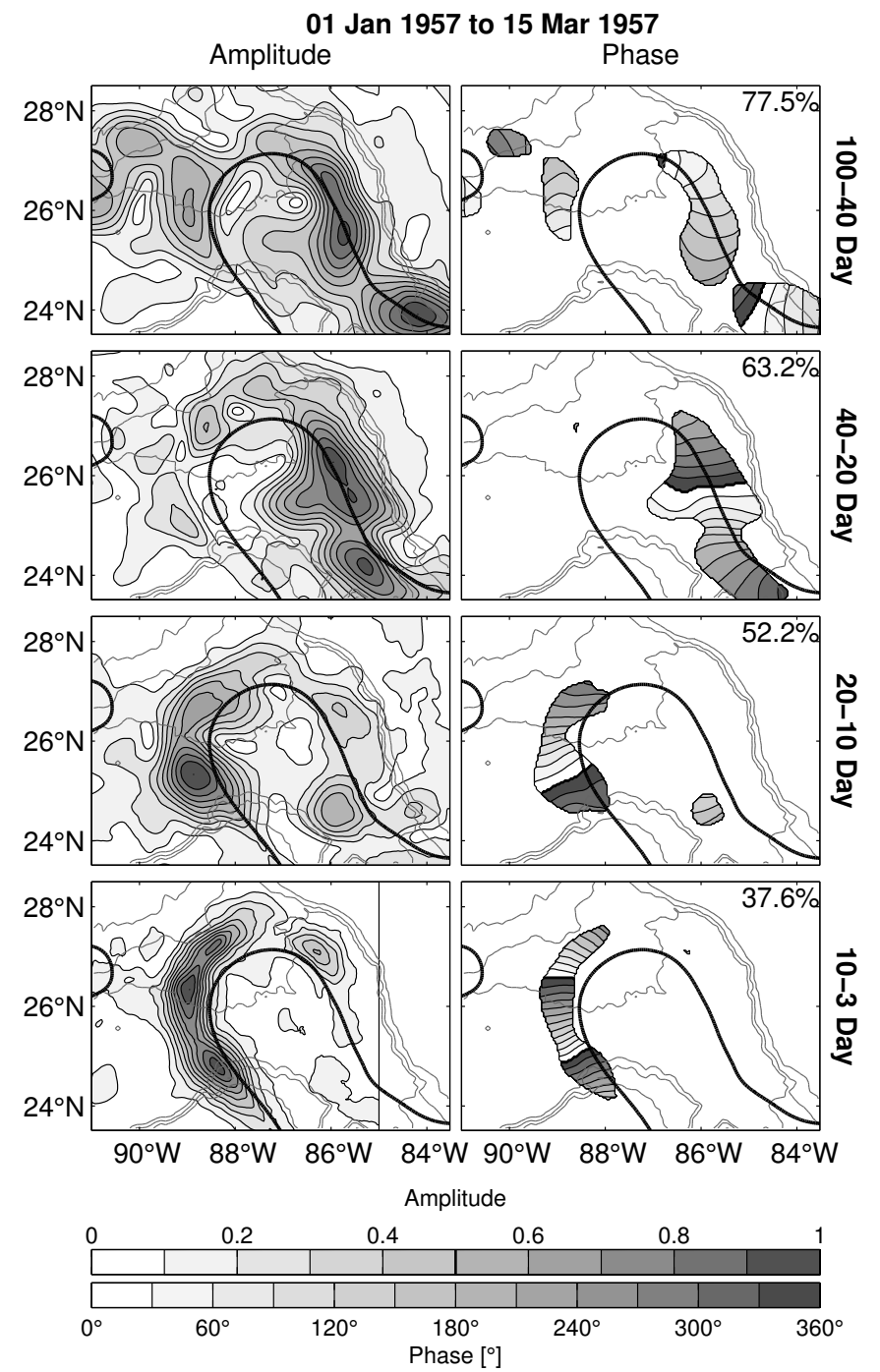

Figure 15: CEOFs of band-passed SSH from free-running HYCOM expt_02.2 during model dates 01 Jan. to 15 Mar. 1957. Frequency bands (rows) increase in frequency from top to bottom. First-mode CEOF amplitude (left column) and phase in degrees (right column) are overlaid with mean Loop Current position (thick black line) from model SSH and bathymetry (gray contours; $1000 \mathrm{~m}$ interval). Percentage of total variance explained by the first mode is printed in the upper-right of each phase plot. Propagation is in the direction of increasing phase (light to dark; right panels). 
541

strongest along the eastern and western edges of the LC, respectively. Unlike the CEOFs for HYCOM31.0, spatial phase fields from the free-running model show both the high- and low-frequency signal propagating along the LC at speeds comparable to observations; recall that HYCOM31.0 high-frequency

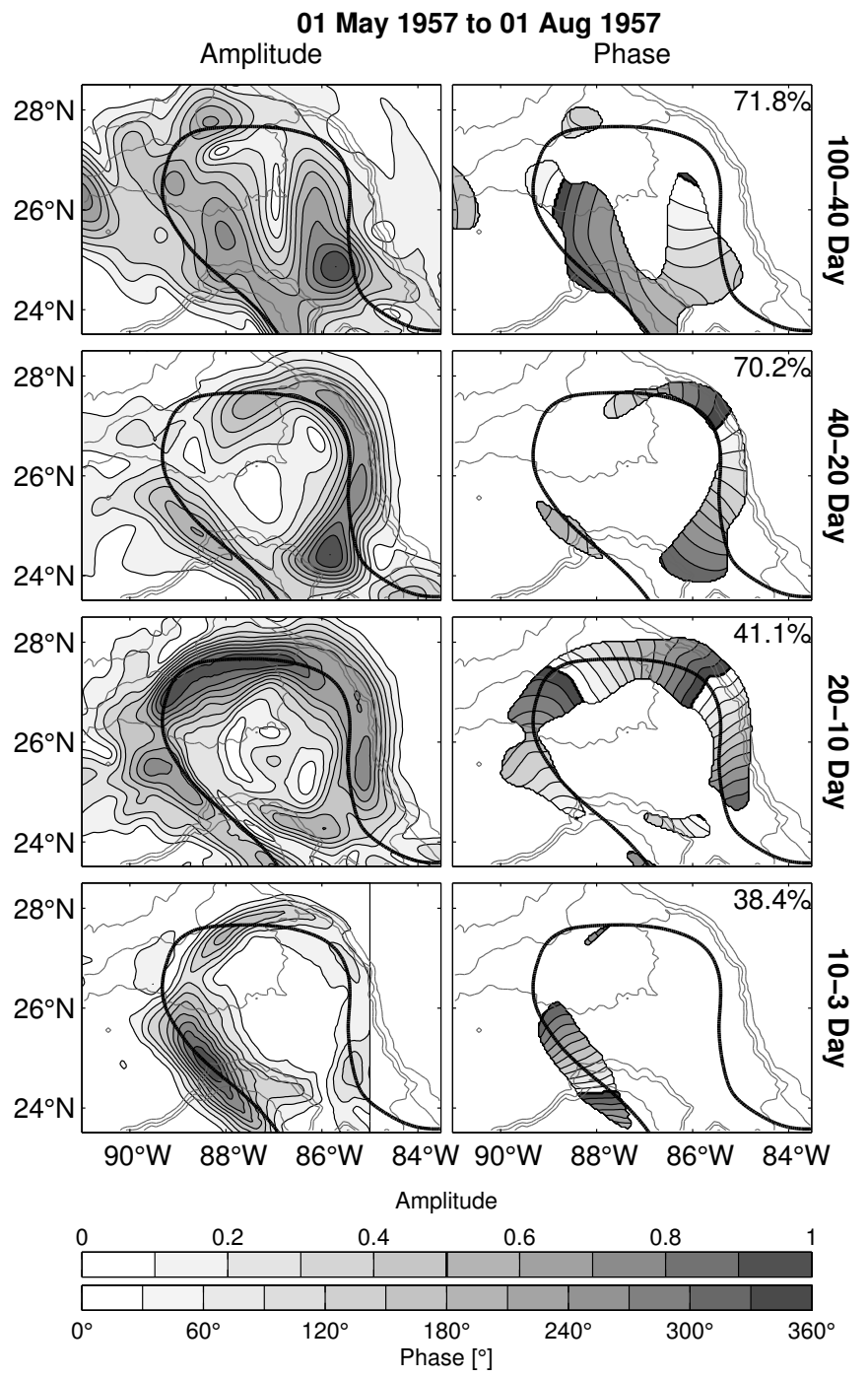

Figure 16: Same as Figure 15, but for free-running model dates 01 May - 01 Aug. 1957. 
phase speeds were unrealistically large. This suggests an improvement over HYCOM31.0 at these high-frequencies. Phase speeds and wavenumbers derived from expt_02.2 matched closely with those from PIES observations for all four frequency bands (Figure 18): differences from observations in both

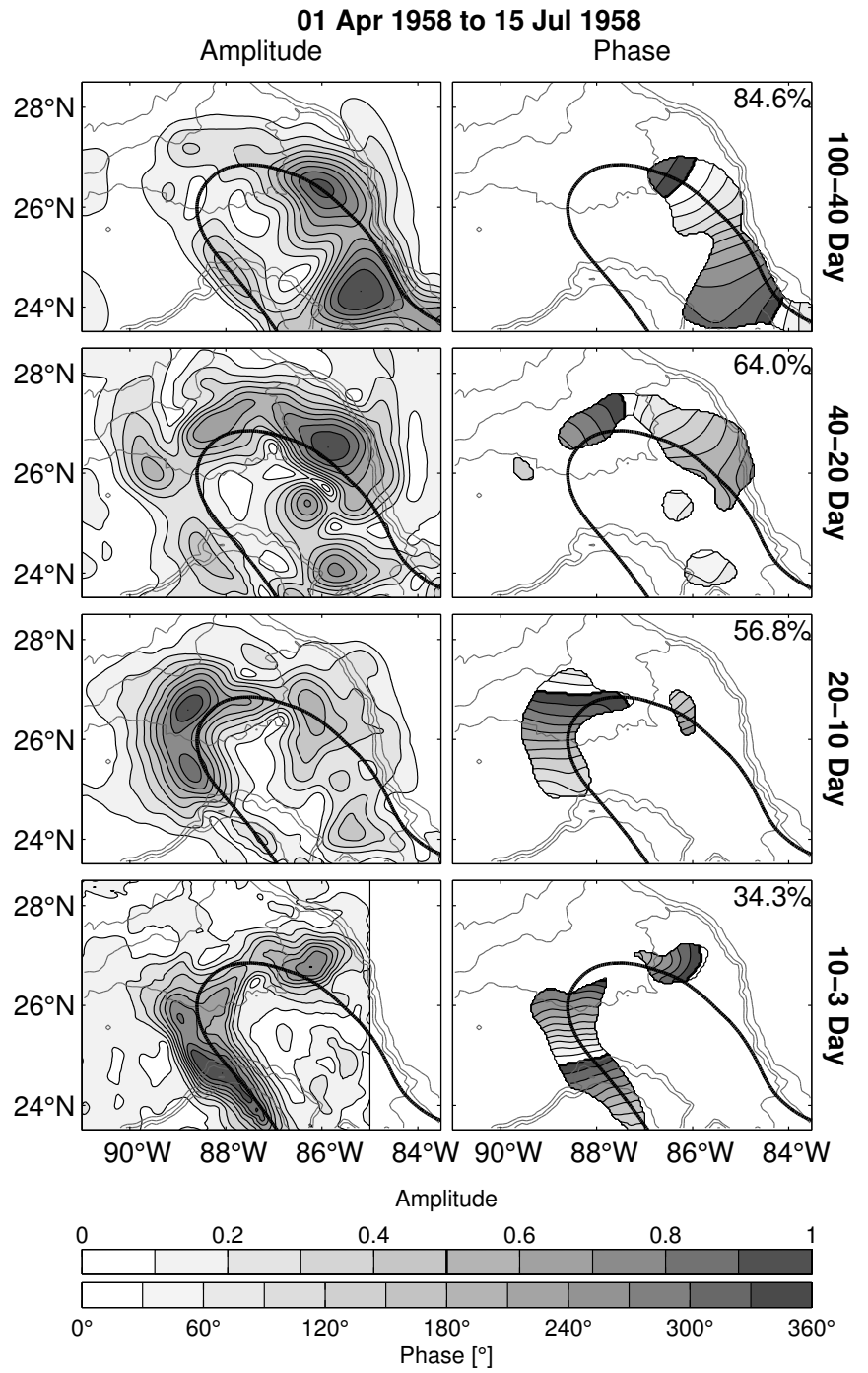

Figure 17: Same as Figure 15, but for free-running model dates 01 Apr. - 15 Jul. 1958. 


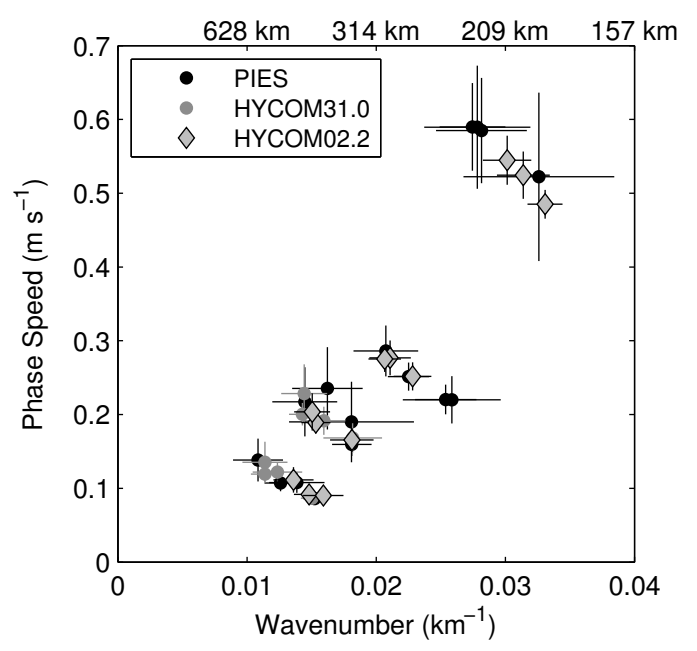

Figure 18: Phase speed vs. wavenumber comparison derived from CEOFs of assimilated (gray circles) and free-running HYCOM (gray diamonds), and from PIES (black) sea surface height for each frequency band. Error bars are standard error. Groupings from bottom to top correspond to 100-40, 40-20, 20-10, and 10-3 day frequency bands.

phase speed and wavenumber were less than $9 \%$ and $4 \%$ in the 100-20 day band and less than $4 \%$ and $1 \%$ in the 20-3 day band. These results imply that the high-frequency altimeter sampling and assimilation could have negative impacts on the accuracy of phase speeds in the data-assimilative HYCOM - this needs to be further investigated by the HYCOM development team.

\subsection{Stream Function Case Study: Upper-Deep Layer Coupling}

Our stream function case studies focus on the 100-40 day band because observations showed coherent upper-deep structure in stream function with a $90^{\circ}$ along-stream phase offset consistent with baroclinic instability (Donohue et al., 2016). Figures 19-21 show three case studies of upper (200 m relative to $2500 \mathrm{~m}$ ) and deep (2500 m) 100-40 day band-passed stream function for eddies Ekman, Franklin, and Hadal, respectively. All three cases 
Table 4: Same as Table 2, but for three eddy periods from free-running expt_02.2.

\begin{tabular}{c|c|ccc}
\hline \hline & $\begin{array}{c}\text { Band } \\
\text { (days) }\end{array}$ & $\begin{array}{c}c_{p} \\
\left(\mathrm{~m} \mathrm{~s}^{-1}\right)\end{array}$ & $\begin{array}{c}k \\
\left(10^{-2} \mathrm{~km}^{-1}\right)\end{array}$ & $\begin{array}{c}\lambda \\
(\mathrm{km})\end{array}$ \\
\hline 1 Jan. - 15 Mar. & $100-40$ & 0.09 & 1.48 & 424.4 \\
1957 & $40-20$ & 0.17 & 1.81 & 346.7 \\
& $20-10$ & 0.28 & 2.11 & 298.1 \\
& $10-3$ & 0.49 & 3.31 & 190.0 \\
\hline 1 May. - 1 Aug. & $100-40$ & 0.11 & 1.36 & 461.9 \\
1957 & $40-20$ & 0.19 & 1.53 & 409.7 \\
& $20-10$ & 0.28 & 2.07 & 304.1 \\
& $10-3$ & 0.52 & 3.14 & 200.2 \\
\hline 1 Apr. - 15 Jul. & $100-40$ & 0.09 & 1.59 & 395.0 \\
1958 & $40-20$ & 0.20 & 1.51 & 417.5 \\
& $20-10$ & 0.25 & 2.28 & 275.4 \\
& $10-3$ & 0.54 & 3.01 & 208.4 \\
\hline \hline
\end{tabular}

demonstrated that strong deep eddies that occur during LCE formation. Additionally, each deep cyclone (anticyclone) tended to be paired, but offset downstream from an upper cyclone (anticyclone) in a pattern indicative of baroclinic instability (Cushman-Roisin, 1994). These patterns, seen in observations, were reproduced by HYCOM31.0. In each case study, examples of these upper-deep pairs are identified in the following descriptions, with the deep cyclone or anticyclone denoted by letters A-D in each figure.

During Eddy Ekman's separation, an upper-deep cyclone pair (A) entered the mapping array from the north on 22 June 2009 and propagated clockwise along the eastern edge of the array to arrive in the southeast portion of the array on 22 July 2009 (Figure 19a-f). At that time, a second upper-deep pair (B), an anticyclonic pair, entered the array from the north. The features were seen in stream function fields from both observations and HYCOM31.0, and matched closely in amplitude, shape, size, and position. Anticyclone pair 

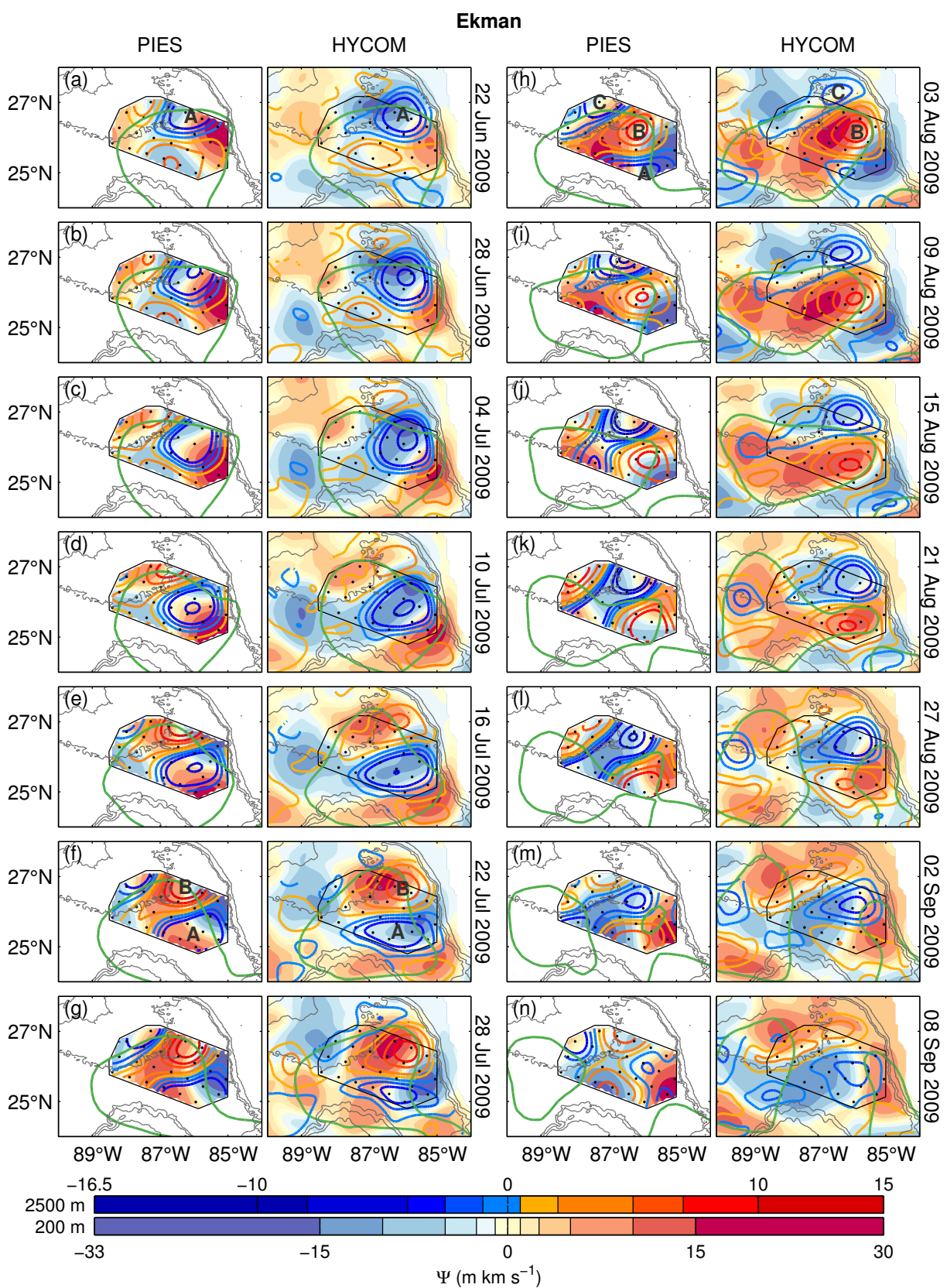

Figure 19: Upper (200 m relative to $2500 \mathrm{~m}$; shading) and deep (2500 m; contours) 10040 day band-passed stream function comparison between observations and HYCOM31.0 at six-day intervals during Eddy Ekman. Green contours indicate altimeter-measured and modeled Loop Current mean position for PIES and HYCOM31.0, respectively. The mapping array is outlined in black with PIES sites indicated by small circles. Gray contours show 1000,2000 , and $3000 \mathrm{~m}$ bathymetry. 


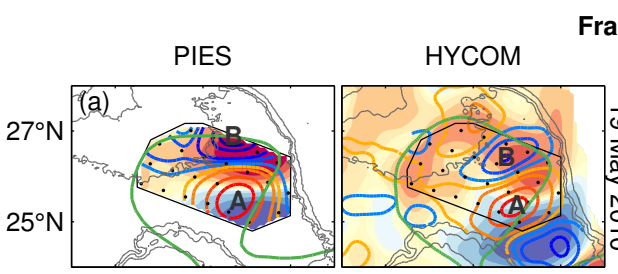

Franklin PIES HYCOM
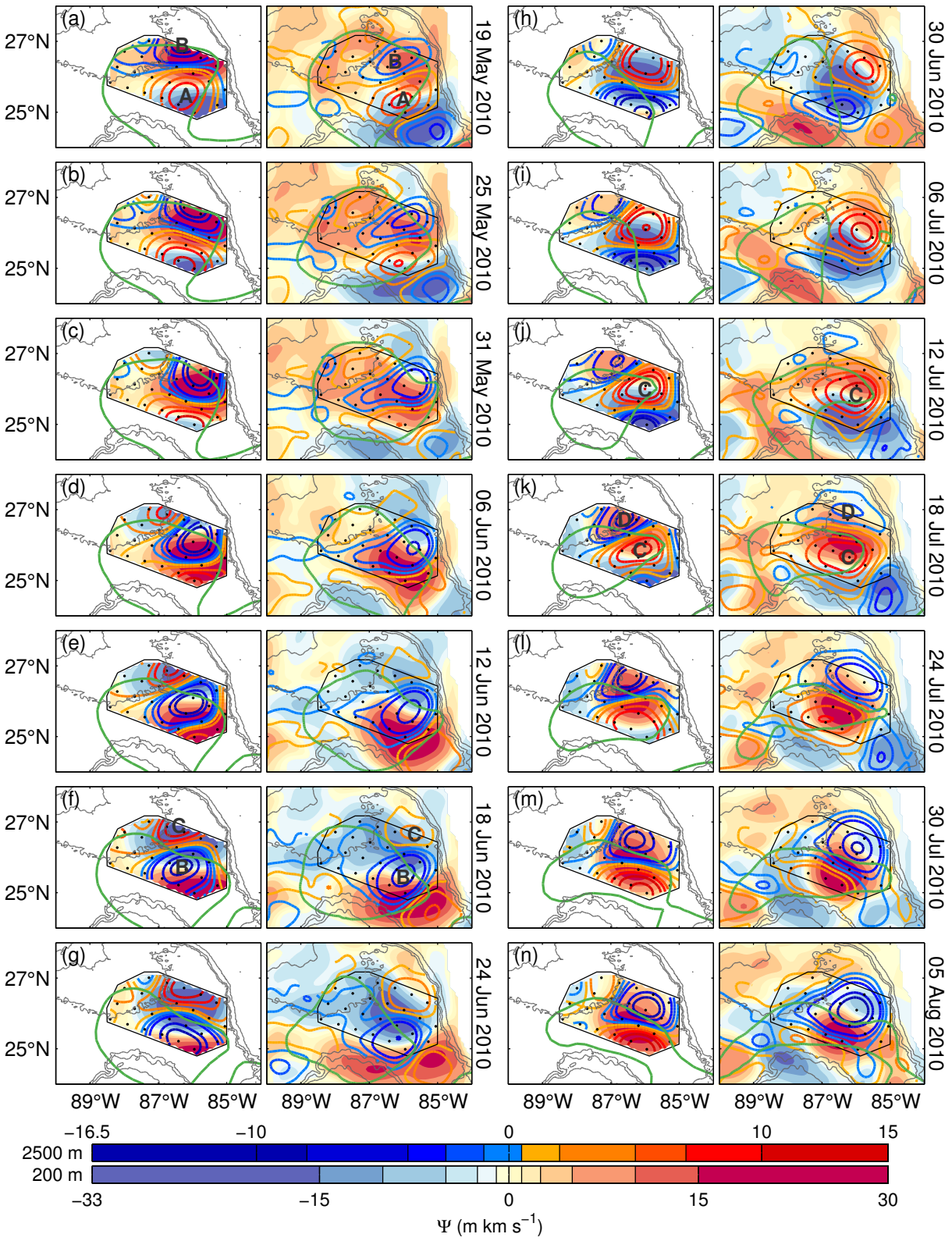

Figure 20: Same as Figure 19, but for Eddy Franklin. 
B followed a similar trajectory to that of A and was found in the central eastern array on 3 August 2009 (Figure $19 \mathrm{f}-\mathrm{h}$ ), at which time eddy pair A appeared to have dissipated in HYCOM31.0. Maps of observed stream function on August 3rd showed A exiting the array to the south, but its fate was unclear due to the spatial limits of the array. From these maps, it seems likely that A and/or B played a role in the first detachment of Ekman: as the deep cyclone associated with pair A exited the array the LC experienced a necking down and eventual detachment on 9 August 2009. On 3 August 2009, upper-deep cyclone pair C entered at the base of the Mississippi Fan near the northwest corner of the array, propagated southward, and appeared to dissipate after Eddy Ekman underwent a detachment around 9 August.

Two offset upper-deep eddy pairs, A and B, were present on 19 May 2010, the first day of the Eddy Franklin case study (Figure 20a), in addition to a more southern cyclone pair seen clearly in HYCOM31.0. Eddy pairs A and B propagated southward along the continental slope and appeared to facilitate Franklin's first detachment around 12 June 2010 (Figures 20 be). Both features were well represented by HYCOM31.0. Anticyclone pair A dissipated around June 6th, while cyclone pair B continued to propagate southward followed by anticyclone pair C, which appeared on 18 June 2010. The latter two pairs assisted in a second detachment of Franklin between the 6th and 12th of July (Figure 20f-j). Cyclone pair D entered the array on the 18 July 2010 and played a role in the final separation of LCE Franklin.

During Eddy Hadal, similar to the Ekman and Franklin cases, a series of southward-propagating cyclone and anticyclone pairs appeared (Figure 21). In the Eddy Hadal case study, the correspondence between observations and 


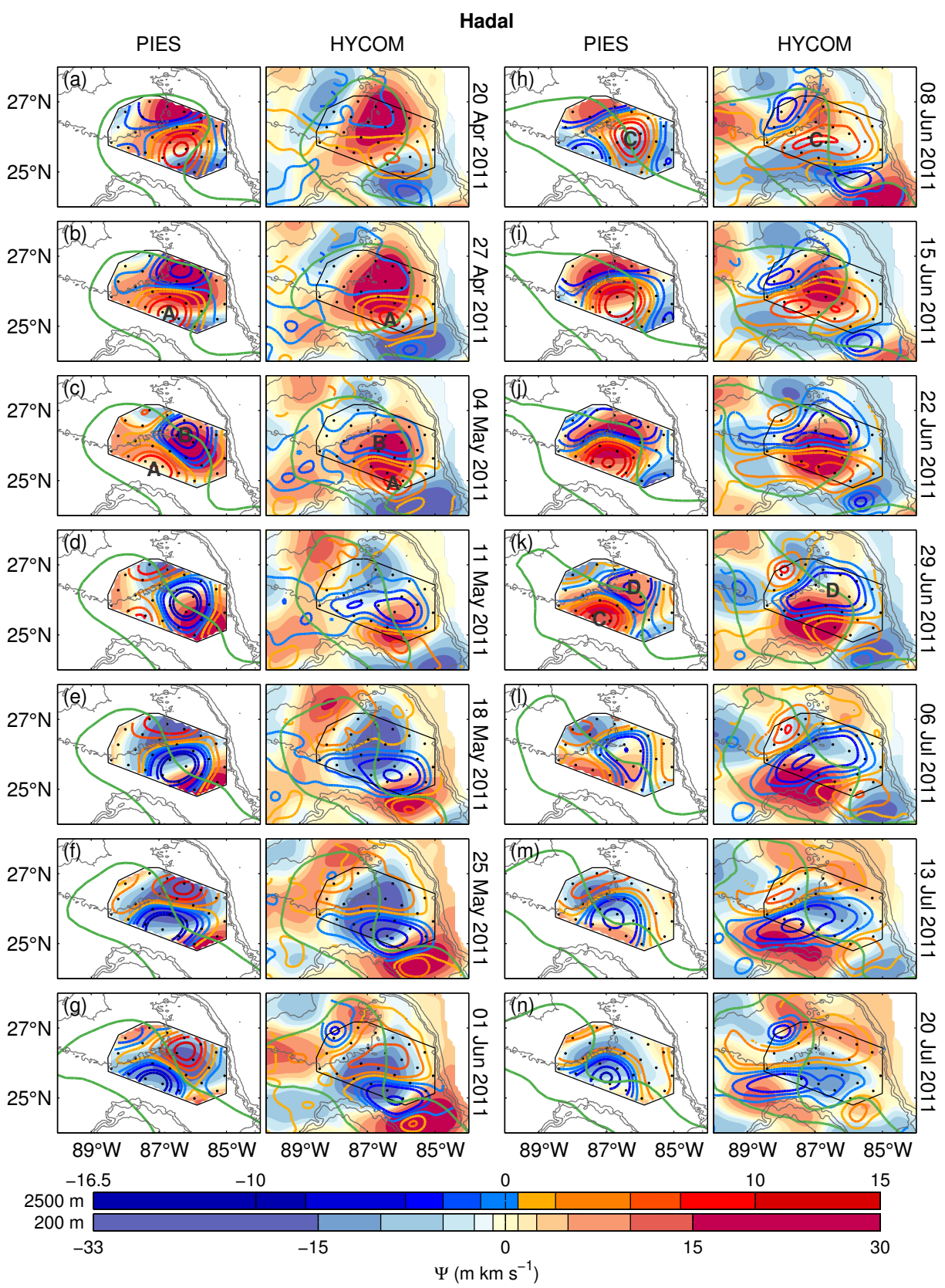

Figure 21: Same as Figure 19, but for Eddy Hadal using one-week intervals. 
HYCOM31.0 was not as strong. Upper and deep eddies occurred in roughly the same location, but deep eddies in HYCOM31.0 appeared more elongated than those of observations.

\section{Discussion and Conclusion}

A full-water-column mesoscale-resolving observational dataset that recorded four LC eddy shedding events permitted an in-depth model-data comparison. The $1 / 25^{\circ}$ data-assimilative GOM HYCOM 31.0 was compared to observations in three categories of metrics: statistical point comparisons, broad-scale spatial comparisons, and process-based phenomenological comparisons. The first category sought to quantify correlations, RMSD, and variance ratios. Because the overall aim of this study was to evaluate the model's ability to accurately represent processes involved in the LCE formation/detachment cycle, the second and third metric categories focused on assessment of the model's representation of LC meander variability, wavenumber-frequency characteristics, and upper-deep coupling during LCE formation.

Statistical point-comparisons showed that in the upper ocean HYCOM31.0 and DynLoop agree well. This was especially true of the temperature comparisons: above-thermocline array-averaged correlation was 0.93 , normalized RMSD ranged between 0.21 and 0.76 , and variance was comparable between model and observations. This indicates that the NCODA vertical projection of synthetic temperature profiles derived from altimeter SSH works well in the Gulf. SSH variance was dominated by the large array-scale nearlyannual cycle of LC advance and retreat; the PIES/HYCOM31.0 SSH time series comparison (summarized in Figure 4b), therefore, showed no statis- 
tical distinction between sites on or off OSTM/Jason-2 altimeter ground tracks. Distinct differences between upper and deep velocity comparisons were apparent: mean velocity correlations above and below $900 \mathrm{~m}$ were approximately 0.7 and 0.2 , respectively, and modeled upper- and deep-ocean velocity variances were, on average, $21 \%$ and $35 \%$ less than observed variances above and below $900 \mathrm{~m}$ depth, respectively.

To focus on the mesoscale circulation, the spatial pattern of SSH variance in four frequency bands was evaluated. In the 100-40 and 40-20 day bands, modeled and observed SSH revealed meanders that grew and propagated downstream along the eastern portion of the LC, with phase speeds between 0.09 and $0.24 \mathrm{~m} \mathrm{~s}^{-1}$. Mean phase speeds from HYCOM31.0 and observations agreed within $8 \%$ and $2 \%$ in the $100-40$ and $40-20$ day band, respectively. Although the spatial variance pattern for the two high-frequency bands (20-10 and 10-3 day) looked similar, propagation speeds did not agree well: model phase speeds were unrealistically large. This was consistent with the result that SSH coherence between HYCOM31.0 and PIES SSH fell off rapidly for frequencies higher than $1 / 20 \mathrm{~d}^{-1}$. We speculate that, for the high-frequencies, altimeter sampling influences the agreement between observations and model, noting that phase speeds determined from a comparable free-running version of GOM HYCOM differed from observed values by less than $9 \%$ for all frequency bands. Liu et al. (2014) assessed the relative skill of a suite of altimeter-derived surface current products and model output. They found that the altimeter-derived products performed slightly better than the $1 / 25^{\circ}$ GOM data-assimilative HYCOM, and suggested that increased data coverage might improve HYCOM's performance. Outstanding questions, such as 
the one raised by the DynLoop program as to whether high-frequency meanders propagate along the full length of the LC, are therefore currently best addressed with a free-running model.

Observations and numerical models indicate that deep eddies play a role in the separation of LCEs (Hurlburt and Thompson, 1980, 1982; Sturges et al., 1993; Welsh and Inoue, 2000; Oey, 2008; Donohue et al., 2015, 2016). Both HYCOM31.0 and observations showed that deep EKE increased during LCE separation, although the amplitude of modeled deep EKE was about half that observed. A comparison of world-wide current meter observations to a free running $1 / 12^{\circ}$ global HYCOM configuration (Scott et al., 2010) showed that the deep kinetic energy was also significantly reduced (by up to a factor of three) when compared to observations, but that data assimilation brought modeled kinetic energy close to observed levels. Scott et al. (2010) did suggest that the quadratic bottom drag value, $C_{d}$, used in HYCOM may play a role in reduced model TKE. Higher resolution may also be necessary when modeling the GOM: recent modeling studies indicate that resolutions higher than $1 / 32^{\circ}$ may be necessary to properly resolve deep EKE (Hurlburt and Hogan 2000; Chassignet and $\mathrm{Xu}$, personal communication).

Within the 100-40 day band, HYCOM31.0 reproduced patterns indicative of baroclinic instability, that is, a vertical offset between upper and deep stream function. While modeled deep eddies differed slightly spatially and temporally from observations, the joint development of an upper ocean meander along the eastern side of the LC and train of upper-deep cyclone/anticyclone pairs that precede separation were contained within the model solution. 
Further analysis of the $1 / 25^{\circ}$ GOM data-assimilative HYCOM would provide insight into LCE formation and separation, offering a larger spatiotemporal window than observational arrays. For example, the trigger for the development of the long wavelength meander is not well understood. Do LC frontal eddies generate deep vorticity as they stretch and move off the Mississippi Fan as suggested by Le Hénaff et al. (2012) or do pre-existing external deep eddies generated near the West Florida Shelf interact with the LC? Interestingly, the HYCOM31.0 case studies in Figures 19-21 suggest that both mechanism might be operating. Model analysis would provide insight into the radiation of the deep energy generated during LCE separation. At the present time, the pathways of deep energy radiation, feedbacks between upper and deep circulation, especially in regions of steep topography, are not well understood due to limited observations.

\section{Acknowledgments}

K. Rosburg wishes to thank Maureen Kennelly and Karen Tracey for frequent information regarding the observational dataset, Dmitry Dukhovskoy for providing insight into the inner workings of the HYCOM model, Michael McDonald for troubleshooting data-access issues during the early stages of this study, and Randy Watts for numerous suggestions and guidance throughout this study. K. Rosburg and K. Donohue acknowledge the support of the University of Rhode Island, National Science Foundation, Research Experience for Undergraduate grant OCE-1156520, and Bureau of Ocean Energy Management contract M08PC20043. E. Chassignet acknowledges the support of the US Department of the Interior, Bureau of Ocean Energy Man- 
agement under the cooperative agreement MC12AC00019. The authors also wish to thank Robert Leben and Cody Hall for supplying unassimilated model output and substantial information about that model.

Baker-Yeboah, S., Watts, D. R., Byrne, D. A., 2009. Measurements of sea surface height variability in the eastern South Atlantic from pressure-sensor equipped inverted echo sounders: baroclinic and barotropic components. J. Atmos. Oceanic Technol. 26 (12), 2593-2609.

Barnett, T., 1983. Interaction of the monsoon and Pacific Trade Wind system at interannual time scales. Part II: The tropical band. Mon. Weather Rev. $112,2380-2387$.

Bendat, J. S., Piersol, A. G., 2000. Random Data: Analysis and Measurement Procedures, third edition Edition. Wiley, New York.

Bleck, R., 2002. An oceanic general circulation model framed in hybrid isopycnic-Cartesian coordinates. Ocean Modelling 4 (1), 55-88.

Bretherton, F. P., Davis, R. E., Fandry, C., 1976. A technique for objective analysis and design of oceanographic experiments applied to MODE-73. In: Deep Sea Research and Oceanographic Abstracts. Vol. 23. Elsevier, pp. 559-582.

Bunge, L., Ochoa, J., Badan, A., Candela, J., Sheinbaum, J., 2002. Deep flows in the Yucatán Channel and their relation to changes in the Loop Current extension. J. Geophys. Res. 107(C12):3233.

Chang, Y.-L., Oey, L.-Y., 2011. Loop Current cycle: Coupled response of the Loop Current with deep flows. J. Phys. Oceanogr. 41 (3), 458-471. 
Chang, Y.-L., Oey, L.-Y., 2012. Why does the Loop Current tend to shed more eddies in summer and winter? Geophys. Res. Lett. 39, L05605.

Chang, Y.-L., Oey, L.-Y., 2013. Loop Current growth and eddy shedding using models and observations: Numerical process experiments and satellite altimetry data. J. Phys. Oceanogr. 43, 669-689.

Chassignet, E., Hurlburt, H., Metzger, E. J., Smedstad, O., Cummings, J., Halliwell, G., Bleck, R., Baraille, R., Wallcraft, A., Lozano, C., Tolman, H., Srinivasan, A., Hankin, S., Cornillon, P., Weisberg, R., Barth, A., He, R., Werner, F., Wilkin, J., 2009. US GODAE: Global Ocean Prediction with the HYbrid Coordinate Ocean Model (HYCOM). Oceanography 22 (2), 64-75.

Chassignet, E. P., Hurlburt, H. E., Smedstad, O. M., Barron, C. N., Ko, D. S., Rhodes, R. C., Shriver, J. F., Wallcraft, A. J., Arnone, R. A., 2005. Assessment of data assimilative ocean models in the Gulf of Mexico using ocean color. In: Sturges, W., Lugo-Fernández, A. (Eds.), Circulation in the Gulf of Mexico: Observations and Models. Vol. 161 of Geophysical Monograph Series. American Geophysical Union, Washington, D.C., pp. $87-100$.

Chassignet, E. P., Hurlburt, H. E., Smedstad, O. M., Halliwell, G. R., Hogan, P. J., Wallcraft, A. J., Baraille, R., Bleck, R., 2007. The HYCOM (HYbrid Coordinate Ocean Model) data assimilative system. J. Marine Syst. 65 (14), 60-83.

Chassignet, E. P., Hurlburt, H. E., Smedstad, O. M., Halliwell, G. R., Wal- 
fraft, A. J., Metzger, E. J., Blanton, B. O., Lozano, C., Rao, D. B., Hogan, P. J., Srinivasan, A., 2006. Generalized vertical coordinates for eddy-resolving global and coastal ocean forecasts. Oceanography 19, 2031.

Chassignet, E. P., Smith, L. T., Halliwell, G. R., Bleck, R., 2003. North Atlantic simulation with the HYbrid Coordinate Ocean Model (HYCOM): Impact of the vertical coordinate choice, reference density, and thermobaricity. J. of Phys. Oceanogr. 33, 2504-2526.

Chérubin, L. M., Sturges, W., Chassignet, E. P., 2005. Deep flow variability in the vicinity of the Yucatan Straits from a high-resolution numerical simulation. J. Geophys. Res. 110 (C4), C04009.

Cione, J. J., Uhlhorn, E. W., Aug. 2003. Sea surface temperature variability in hurricanes: Implications with respect to intensity change. Mon. Weather Rev. 131 (8), 1783-1796.

Cochrane, J., 1972. Separation of an anticyclone and subsequent development in the Loop Current (1969). In: Capuro, L., Reids, J. (Eds.), Contributions on the Physical Oceanography of the Gulf of Mexico. No. 2 in Texas A\&M University Oceanographic Studies. Gulf Publishing Co., Houston, TX, pp. pp. 91-106.

Cummings, J. A., 2005. Operational multivariate ocean data assimilation. Q. J. Roy. Meteor. Soc. 131 (613), 3583-3604.

Cummings, J. A., Smedstad, O. M., 2013. Variational data assimilation for the global ocean. In: Park, S. K., Xu, L. (Eds.), Data Assimilation for At- 
mospheric, Oceanic and Hydrologic Applications (Vol. II). Springer Berlin Heidelberg, pp. 303-343.

Cushman-Roisin, B., 1994. Introduction to Geophysical Fluid Dynamics. Prentice-Hall, New Jersey.

Donohue, K. A., Watts, D. R., Hamilton, P., Leben, R., Kennelly, M., 2016. Loop Current Eddy separation and baroclinic instability. Dyn. Atmos. Oceans (accepted).

Donohue, K. A., Watts, D. R., Hamilton, P., Leben, R., Kennelly, M., LugoFernández, A., 2015. Gulf of Mexico Loop Current path variability. Dyn. Atmos. Oceans (accepted).

Donohue, K. A., Watts, D. R., Tracey, K. L., Greene, A. D., Kennelly, M., 2010. Mapping circulation in the Kuroshio Extension with an array of current and pressure recording inverted echo sounders. J. Atmos. Oceanic Technol. 27, 507-527.

Dukhovskoy, D. S., Leben, R. R., Chassignet, E. P., Hall, C. A., Morey, S. L., Nedbor-Gross, R., 2015. Characterization of the uncertainty of Loop Current metrics using a multidecadal numerical simulation and altimeter observations. Deep Sea Res. Pt. I 100, 140-158.

Fox, D., Teague, W., Barron, C., Carnes, M., Lee, C., 2002. The Modular Ocean Data Analysis System (MODAS). J. Atmos. Ocean Tech. 19, 240252.

Gopalakrishnan, G., Rudnick, D. L., Owens, W. B., 2013b. State estimates 
and forecasts of the Loop Current in the Gulf of Mexico using the MITgcm and its adjoint. J. Geophys. Res. Oceans 118, 3292-3314.

Hamilton, P., Donohue, K., Hall, C., Leben, R. R., Quian, H., Sheinbaum, J., Watts, D. R., 2014. Observations and dynamics of the Loop Current. Tech. Rep. OSC Study BOEM 2015-006, US Dept. of the Interior, Bureau of Ocean Energy Management, Gulf of Mexico OSC Region, New Orleans, LA.

URL http://www.po.gso.uri.edu/dynamics/pub_index.html

Hamilton, P., Lugo-Fernández, A., Sheinbaum, J., 2016. A Loop Current experiment: Field and remote measurements. Dyn. Atmos. Ocean. (in press).

Hannachi, A., Jolliffe, I., Stephenson, D., 2007. Empirical orthogonal functions and related techniques in atmospheric science: A review. Intl. J. of Clim. 27 (9), 1119-1152.

Harris, F., 1978. On the use of windows for harmonic analysis with the discrete fourier transform. Proceedings of the IEEE 66 (1), 51-83.

Hurlburt, H. E., Hogan, P. J., 2000. Impact of $1 / 8^{\circ}$ to $1 / 64^{\circ}$ resolution on Gulf Stream model-data comparisons in basin-scale subtropical Atlantic Ocean models. Dyn. Atmos. Oceans 32, 283-329.

Hurlburt, H. E., Thompson, J. D., 1980. A numerical study of Loop Current intrusions and eddy sheeding. J. Phys. Oceanogr. 10, 1611-1651.

Hurlburt, H. E., Thompson, J. D., 1982. The dynamics of Loop Current and shed eddies in a numerical model of the Gulf of Mexico. In: Nihoul, J. 
(Ed.), Hydrodynamics of Semi-enclosed Seas. Elsevier Sci., New York, pp. 243-298.

Kantha, L., Choi, J.-K., Schaudt, K. J., Cooper, C. K., 2005. A regional dataassimilative model for operational use in the Gulf of Mexico. In: Sturges, W., Lugo-Fernández, A. (Eds.), Circulation in the Gulf of Mexico: Observations and Models. Vol. 161 of Geophysical Monograph Series. American Geophysical Union, Washington, D.C., pp. pp. 165-180.

Le Hénaff, M., Kourafalou, V. H., Dussurget, R., Lumpkin, R., 2014. Cyclonic activity in the eastern Gulf of Mexico: Characterization from alongtrack altimetry and in situ drifter trajectories. Prog. in Oceanogr. 120, $120-138$.

Le Hénaff, M., Kourafalou, V. H., Morel, Y., Srinivasan, A., 2012. Simulating the dynamics and intensification of cyclonic Loop Current Frontal Eddies in the Gulf of Mexico. J. Geophys. Res. 117, C02034.

Leben, R., 2005. Altimeter-derived Loop Current metrics. In: Sturges, W., Lugo-Fernández, A. (Eds.), Circulation in the Gulf of Mexico: Observations and Models. Vol. 161 of Geophysical Monograph Series. American Geophysical Union, Washington, D.C., pp. pp. 181-201.

Leben, R. R., Born, G. H., Engebreth, B. R., 2002. Operational altimeter data processing for mesoscale monitoring. Marine Geodesy 25, 3-18.

Leben, R. R., Hall, C. A., Hoffman, N. G., 2012. The relationship between Loop Current separation period and retreat latitude revisited. In: McKay, 
M., Nides, J. (Eds.), Proceedings: Twenty-Sixth Gulf of Mexico Information Transfer Meeting, March 2011. U.S. Dept. of the Interior, Bureau of Ocean Energy Management, Gulf of Mexico OCS Region: New Orleans, LA, pp. 37-41 (OCS Study BOEM 2012-107).

Lin, I.-I., Wu, C.-C., Pun, I.-F., Ko, D.-S., Sep. 2008. Upper-ocean thermal structure and the Western North Pacific category 5 typhoons. Part I: Ocean features and the category 5 typhoons' intensification. Mon. Weather Rev. 136 (9), 3288-3306.

Liu, Y., Weisberg, R. H., 2011. Evaluation of trajectory modeling in different dynamic regions using normalized cumulative Lagrangian separation. J. Geophys. Res. 116, C09013.

Liu, Y., Weisberg, R. H., 2012. Seasonal variability on the West Florida Shelf. Prog. in Oceanogr. 104, 80-98.

Liu, Y., Weisberg, R. H., Vignudelli, S., Mitchum, G. T., 2014. Evaluation of altimetry-derived surface current products using lagrangian drifter trajectories in the eastern Gulf of Mexico. J. Geophys. Res. Oceans 119, $2827-2842$.

Lugo-Fernández, A., 2007. Is the Loop Current a chaotic oscillator? J. Phys. Oceanogr. 37, 471-489.

Lugo-Fernández, A., Leben, R. R., 2010. On the linear relationship between Loop Current retreat latitude and eddy separation period. J. Phys. Oceanogr. 40 (12), 2778-2784. 
Maul, G. A., 1977. The annual cycle of the Gulf Loop Current, part I, Observations during a one-year time series. J. Mar. Res. 35, 29-47.

Meinen, C. S., Watts, D. R., 2000. Vertical structure and transport on a transect across the North Atlantic Current near $42^{\circ} \mathrm{N}$ : Time series and mean. J. Geophys. Res.: Oceans 105 (C9), 21869-21891.

Metzger, E. J., Smedstad, O. M., Thoppil, P. G., Hurlburt, H. E., Cummings, J. A., Wallcraft, A. J., Zamudio, L., Franklin, D. S., Posey, P. G., Phelps, M. W., Hogan, P. J., L., B. F., DeHaan, C. J., 2014. US Navy operational global ocean and Arctic ice prediction systems. Oceanography 27 (3), 3243.

Nedbor-Gross, R., Dukhovskoy, D. S., Bourassa, M., Morey, S. L., Chassignet, E. P., 2014. Investigation of the relationship between the Yucatán Channel transport and the Loop Current area in a multi-decadal numerical simulation. Mar. Technol. Soc. J. 48 (4), 15-26.

Nguyen, T.-T., Morey, S. L., Dukhovskoy, D. S., Chassignet, E. P., 2015. Nonlocal impacts of the Loop Current on cross-slope near-bottom flow in the northeastern Gulf of Mexico. Geophys. Res. Lett. 42 (8), 2926-2933.

Oey, L. Y., 2008. Loop Current and deep eddies. J. Phys. Oceanogr. 38, 1426-1449.

Paris, C. B., Le Hénaff, M., Aman, Z. M., Subramaniam, A., Helgers, J., Wang, D.-P., Kourafalou, V. H., Srinivasan, A., 2012. Evolution of the Macondo well blowout: Simulating the effects of the circulation and synthetic 
dispersants on the subsea oil transport. Environ. Sci. Technol. 46 (24), 13293-13302.

Park, J.-H., Watts, D. R., Donohue, K. A., Tracey, K. L., 2012. Comparisons of sea surface height variability observed by pressure-recording inverted echo sounders and satellite altimetry in the Kuroshio Extension. J. of Oceanogr. 68 (3), 401-416.

Schmitz, W. J. J., 2005. Cyclones and westward propagation in the shedding of anticyclonic rings from the Loop Current. In: Sturges, W., LugoFernández, A. (Eds.), Circulation in the Gulf of Mexico: Observations and Models. Vol. 161 of Geophysical Monograph Series. American Geophysical Union, Washington, D.C., pp. 241-261.

Scott, R., Arbic, B. K., Chassignet, E. P., Coward, A. C., Maltrud, M., Srinivassan, A., Vargese, A., 2010. Total kinetic energy in four global eddying ocean circulation models and over 5000 current meter records. Ocean Modeling 32, 157-169.

Shay, L. K., Jaimes, B., Brewster, J. K., Meyers, P., McCaskill, E. C., Uhlhorn, E., Marks, F., Halliwell Jr., G. R., Smedstad, O. M., Hogan, P., 2011. Airborne ocean surveys of the Loop Current complex from NOAA WP-3D in support of the Deepwater Horizon oil spill. In: Liu, Y., MacFadyen, A., Ji, Z.-G., Weisberg, R. H. (Eds.), Monitoring and Modeling the Deepwater Horizon Oil Spill: A Record-Breaking Enterprise. Vol. 195 of Geophysical Monograph Series. American Geophysical Union, Washington, D.C., pp. 131-151. 
Sturges, W., Evans, J. C., Welsh, S., Holland, W., Feb. 1993. Separation of warm-core rings in the Gulf of Mexico. J. Phys. Oceanogr. 23 (2), 250-268.

Sturges, W., Leben, R. R., 2000. Frequency of ring separations from the Loop Current in the Gulf of Mexico: A revised estimate. J. Phys. Oceanogr. 30, $1814-1818$.

Taylor, K. E., Apr. 2001. Summarizing multiple aspects of model performance in a single diagram. J. Geophys. Res. 106 (D7), 7183-7192.

Thompson, R. O. R. Y., 1979. Coherence significance levels. J. of Atmos. Sci. 36 (10), 2020-2021.

Vukovich, F. M., 1988. Loop Current boundary variations. J. Geophys. Res.: Oceans 93 (C12), 15585-15591.

Walker, N., Myint, S., Babin, A., Haag, A., 2003. Advances in satellite radiometry for the surveillance of surface temperatures, ocean eddies and upwelling processes in the Gulf of Mexico using GOES-8 measurements during summer. Geophys. Res. Let. 30 (16), 1854.

Watts, D. R., Tracey, K. L., Friedlander, A. I., 1989. Producing accurate maps of the Gulf Stream thermal front using objective analysis. J. Geophys. Res.: Oceans 94 (C6), 8040-8052.

Watts, R. D., Qian, X., Tracey, K. L., 2001. Mapping abyssal currents and pressure fields under the meandering Gulf Stream. J. Atmos. Ocean Tech. 18, 1052-1067. 
Welsh, S. E., Inoue, M., 2000. Loop Current rings and the deep circulation in the Gulf of Mexico. J. Geophys. Res.: Oceans 105 (C7), 16951-16959.

Xu, F.-H., Chang, Y.-L., Oey, L.-Y., Hamilton, P., 2013. Loop Current growth and eddy shedding using models and observations: analyses of the july 2011 eddy-shedding event. J. Phys. Oceanogr. 43, 1015-1027.

Yablonsky, R. M., Ginis, I., Sep. 2012. Impact of a warm ocean eddy's circulation on hurricane-induced sea surface cooling with implications for hurricane intensity. Mon. Weather Rev. 141 (3), 997-1021.

Yin, X. Q., Oey, L. Y., 2007. Bred-ensemble ocean forecast of Loop Current and rings. Ocean Modell. 17, 300-326.

Zeng, X., Li, Y., He, R., 2015. Predictability of the Loop Current variation and eddy shedding process in the Gulf of Mexico using an artificial neural network approach. J. Atmos. Oceanic Technol. 32 (5), 1098-1111. 
Figure 21 - Stream Fn Hadal PIES

\section{Hadal}

HYCOM

PIES

HYCOM
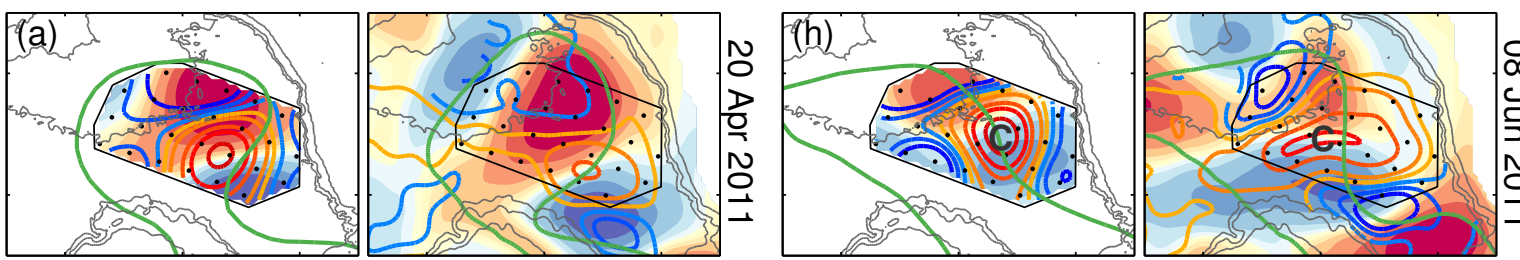

$(-\mathrm{b})$

$27^{\circ} \mathrm{N}$

$25^{\circ} \mathrm{N}$
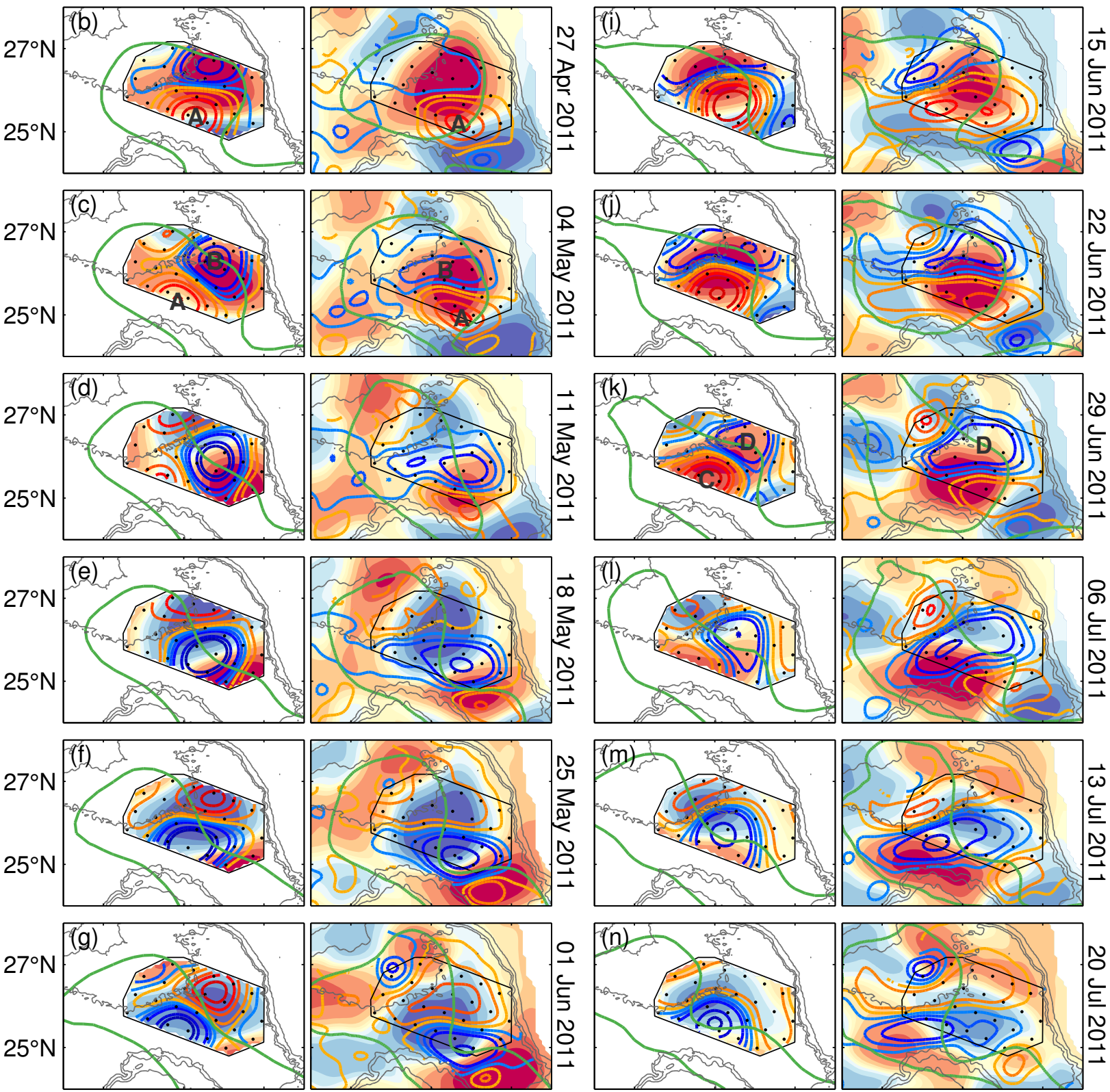

$89^{\circ} \mathrm{W} \quad 87^{\circ} \mathrm{W} \quad 85^{\circ} \mathrm{W} \quad 89^{\circ} \mathrm{W} \quad 87^{\circ} \mathrm{W} \quad 85^{\circ} \mathrm{W}$

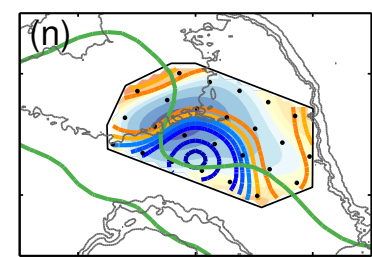

$89^{\circ} \mathrm{W} \quad 87^{\circ} \mathrm{W} \quad 85^{\circ} \mathrm{W}$

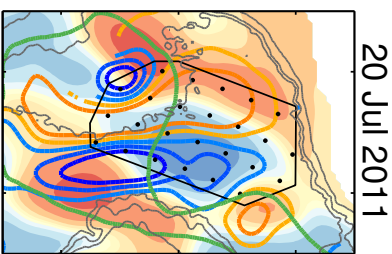

$-16.5$

$-10$

0

$89^{\circ} \mathrm{W} \quad 87^{\circ} \mathrm{W} \quad 85^{\circ} \mathrm{W}$

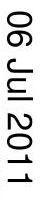

